ISSN: 0213-2060

DOI: https://doi.org/10.14201/shhme202139195122

\title{
IDENTIDAD Y DIMENSIÓN SOCIAL DE LA CONSTRUCCIÓN PLENOMEDIEVAL ECLESIÁSTICA EN SEGOVIA Y SEPÚLVEDA ENTRE LOS SIGLOS XI Y XIII: SIMILITUDES Y DIVERGENCIAS ${ }^{1}$
}

\author{
Identity and Social Dimension of Eclesiastic Construcion in High Middle Ages in \\ Segovia and Sepulveda between $11^{\text {th }}$ and $13^{\text {th }}$ centuries: Similarities and Divergences
}

Rocío MAIRA VIDAL

Dra. Arquitecta. Instituto de Historia. Centro de Ciencias Humanas y Sociales del CSIC. C/Albasanz 26-28. 28037-MADRID. C.e: rociomaira@enjarje.com.ORCID: orcid.org/0000-0001-5408-0067

Recibido: 2021-01-30

Revisado: 2021-02-27

Aceptado: 2021-03-09

RESUMEN: El estudio de la construcción y los recursos utilizados para llevar a cabo los edificios erigidos entre los siglos XI y XIII resulta especialmente interesante porque permite conocer ciertos aspectos de la sociedad medieval que no pueden analizarse de otro modo. En este artículo se presentan los resultados del estudio comparativo de los edificios eclesiásticos construidos en esta cronología en Segovia y Sepúlveda. Ambas poblaciones, próximas entre sí, presentan semejanzas significativas en la tipología arquitectónica y sus elementos más representativos. Sin embargo, existen importantes divergencias en los materiales y técnicas empleados en su construcción, propios del territorio en que se enclavan, pero que también reflejan los cambios sociales y políticos en ambas ciudades a lo largo de este periodo de su historia.

Palabras clave: Construcción medieval; costes; recursos; Sepúlveda; Segovia; petrificación de la riqueza.

ABSTRACT: The study of the construction and resources used to build medieval churches between $11^{\text {th }}$ and $13^{\text {th }}$ centuries is particularity interesting since it allows

1 Esta investigación se ha desarrollado dentro del proyecto «Petrifying Wealth. The Southern European Shift to Masonry as Collective Investment in Identity, c. 1050-1300» del CCHS-CSIC Instituto de Historia, financiado por el programa de investigación e innovación Horizonte 2020 de la Unión Europea bajo el acuerdo n. ${ }^{\circ}$ 695515. Mi agradecimiento a Ana Rodríguez y Therese Martín, investigadoras del proyecto "Petrifying Wealth. The Southern European Shift to Masonry as Collective Investment in Identity, c. 1050-1300", por la revisión de este texto, y a Enrique Capdevila, responsable TIC. 
understanding some characteristics of medieval society, which cannot be analysed in any other way. This paper presents the results of the comparative study of ecclesiastical buildings constructed during this chronology in Segovia and Sepúlveda. The architectural typology and some representative structural elements reveal similarities between both cities, located next to each other. However, there are important differences between materials and techniques used in their construction as a result of the place they are located in, and the social and politic changes that took place in this historical period. wealth.

Keywords: Medieval Construction; costs; resources; Sepúlveda; Segovia; petrifying

SUMARIO: 0 La actividad edilicia entre los siglos XI y XIII. Segovia y Sepúlveda, Comunidades de Villa y Tierra. 1 Tipología arquitectónica de sus iglesias. 2 Elementos constructivos singulares. 2.1 Torres, bóvedas y husillos. 2.2 Pórticos y portadas. 2.3 Los abovedamientos de la iglesia. 3 Técnicas constructivas y recursos empleados en la construcción de las iglesias. 4 Hacia unas conclusiones: los costes en la construcción medieval de Segovia y Sepúlveda. 5 Referencias bibliográficas.

0 La actividad edilicia entre los siglos xi y XiII. Segovia y Sepúlveda, Comunidades de Villa y Tierra

En el siglo XII, la frontera con el mundo musulmán se situaba bastante más al sur de Segovia por lo que debió constituir un periodo de relativa estabilidad en la zona. La lucha de poderes locales, regionales y supraregionales, que probablemente podían resultar más desestabilizadores para la población que una amenaza exterior, quizá no contó con una relevancia suficientemente significativa en este momento, propiciando así un periodo idóneo para la construcción. La gran cantidad de edificios conservados ${ }^{2}$ que datan de los siglos XI al XIII son prueba de ello, aún teniendo en cuenta que suponen únicamente una pequeña parte del total, ya que muchos no se conservan y sólo ha quedado constancia de ellos en el registro escrito ${ }^{3}$.

Segovia y Sepúlveda formaban parte de las Comunidades de Villa y Tierra ${ }^{4}$, zona fronteriza poco segura en el siglo xI, lo que se reflejó en el llamado Fuero Breve o Latino. Este documento, vigente hasta 1305, año en el que está fechado el Fuero Extenso,

2 Se considera que se ha conservado un número importante de iglesias en la ciudad de Segovia teniendo en cuenta el área que ocupan la ciudad y sus arrabales. Por otro lado, el número es elevado si se valora lo que supondría el coste y los recursos empleados por la población en un periodo de tiempo relativamente corto, prácticamente un siglo, momento en el que se concentra la mayor parte de la actividad edilicia de la ciudad, tanto eclesiástica como civil.

3 El equipo del proyecto «Petrifying Wealth. The Southern European Shift to Masonry as Collective Investment in Identity, c. 1050-1300» está registrando en su base de datos y geolocalizando en los mapas tanto los edificios conservados como aquellos que conocemos a través de su mención en las fuentes históricas, lo que nos permite realizar esta afirmación.

4 Villar García, Luis Miguel. «La formación de las Comunidades de Villa y Tierra en las fronteras del Duero». Biblioteca: Estudio e investigación, 2009, vol. 24, pp. 77-103. 


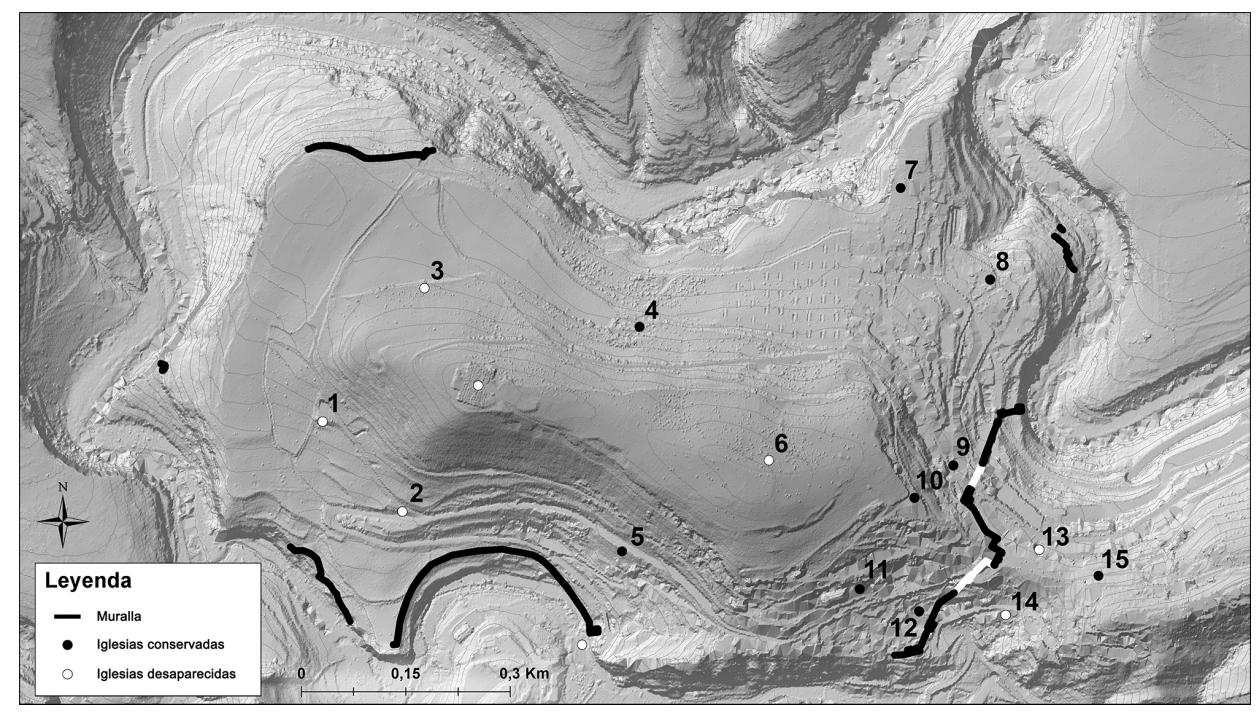

FIgURA 1. Iglesias construidas en Sepúlveda en la cronología de estudio, conservadas (negro) y desaparecidas (blanco). Imagen realizada por Enrique Capdevila a partir de los datos estudiados por Fabio Giovannini y Enrique Capdevila. 1. Santa Eulalia; 2. San Juan; 3. San Sebastián; 4. San Pedro; 5. San Andrés; 6. San Martín; 7. Nuestra Señora de la Peña; 8. San Millán; 9. Santos Justo y Pastor; 10. El Salvador; 11. Santiago; 12. San Esteban; 13. Santo Domingo; 14. San Gil; 15. San Bartolomé.

permitía asentarse a nuevos habitantes que tuviesen antecedentes criminales en otros lugares de Castilla, lo que da una idea de la inestabilidad de la zona y la dificultad para contar con población permanente ${ }^{5}$. La fase inicial de esta política de repoblación se organizó en torno a tres centros: Sepúlveda, Cuéllar y Segovia ${ }^{6}$. El más importante de ellos era Sepúlveda; sin embargo, desde 1120, con la restauración medieval de su obispado, Segovia fue sustituyendo a Sepúlveda como centro del poder político del territorio.

Bartolomé Herrero destaca la cualidad rural de su población afirmando que los dos motores principales de la economía serían la agricultura y la ganadería; sin embargo sorprendentemente no menciona la construcción. Debió ser sin duda una de las actividades que movilizó más personas, dinamizando la economía de estas poblaciones habida

5 Martínez Díez, Gonzalo. «La repoblación de la Extremadura castellana y las Comunidades de Villa y Tierra». En Muñoz Gómez, Víctor (coord.). Las Comunidades de Villa y Tierra: dinámicas históricas y problemáticas actuales. Murcia: Editum, 2012, pp. 19-36.

6 Asenjo González, María. "La repoblación de las Extremaduras (s. X-XIII)». En Actas del coloquio de la $V$ asamblea general de la sociedad española de estudios medievales. Zaragoza: Departamento de Cultura y Educación, 1991, pp. 73-99.

7 Bartolomé Herrero, Bonifacio. «Espacio, Iglesia y Sociedad en las Tierras de Segovia durante los siglos XI y XII». En Enciclopedia del románico en Castilla León. Segovia. Tomo I. Aguilar de Campoo: Fundación Santa María la Real, 2007, pp. 17-47. 
IDENTIDAD Y DIMENSIÓN SOCIAL DE LA CONSTRUCCIÓN PLENOMEDIEVAL ECLESIÁSTICA EN SEGOVIA Y SEPÚLVEDA ENTRE LOS SIGLOS XI Y XIII: SIMILITUDES Y DIVERGENCIAS ROCÍO MAIRA VIDAL

cuenta de la gran cantidad de iglesias que se estaban construyendo en este periodo, a las que habría que sumar los edificios laicos.

El transporte entre las canteras y la obra, a pesar de no distar más de $30 \mathrm{~km}^{8}$ en la mayor parte de los casos, era complicado y costoso. La ejecución de los edificios en piedra requería la participación de canteros especializados, pero también de carpinteros para la ejecución de las estructuras auxiliares de madera, andamios, cimbras y grúas, que permitían elevar las cargas y sostener las estructuras durante el proceso constructivo. Todo ello requería un tejido social adecuado, con las infraestructuras necesarias y con mano de obra especializada para llevar a cabo estos trabajos.

Algunos sistemas constructivos utilizados no requerían de mano de obra especializada. Este tipo de operarios podían ejecutar muchas actividades, cargar el material, llevar agua para la aplicación de los morteros o montar ciertos tramos de muro entre otras. Se trataba de personal fácilmente sustituible porque no requería tener conocimientos previos significativos para realizar estas tareas. La especialización de los trabajadores, entendida como la cualificación necesaria para la realización de trabajos complejos que requieren conocimientos específicos, elevaría el precio de contratación. La comparación realizada tiene en cuenta esta característica para poder valorar los costes de la obra9

En Segovia se conservan actualmente veinte iglesias, la mitad de ellas situadas en el interior de las murallas ${ }^{10}$ y la otra mitad extramuros ${ }^{11}$. Aunque en algunos casos hay constancia de edificaciones previas ${ }^{12}$, la construcción de buena parte de los edificios conservados se concentra entre la segunda mitad del siglo XII y la primera del XIII ${ }^{13}$. En muy

8 Alfaro Suescun, Egoitz. «La arquitectura eclesiástica en Álava y Treviño durante los siglos XII-XIII: promotores, constructores y significados en un momento de transición». Arqueología de la Arquitectura, 2017, vol. 14, pp. 1-28.

9 Evidentemente habría situaciones intermedias, con trabajadores de cierta cualificación que realizarían trabajos muy diversos, sin embargo, la comparación de las actividades más especializadas frente las que requieren menor cualificación es la que permite valorar la variación del coste entre distintas estructuras. La estandarización de los procesos de la obra, generando una cadena de actividades, habría permitido optimizar los tiempos repercutiendo en el coste final.

${ }_{10}$ Las iglesias de San Andrés, San Esteban, San Juan de los Caballeros, San Martín, San Miguel Arcángel, San Nicolás de Bari, San Pedro de los Picos, San Quirce, San Sebastián y la Santísima Trinidad.

${ }_{11}$ Las iglesias de San Blas, San Clemente, San Justo, San Lorenzo, San Marcos, San Millán, El Salvador, Santa Eulalia, Santo Tomás y la Veracruz.

12 La nave de la iglesia de San Martín formaba parte del edificio anterior, un templo de planta centralizada que posteriormente se prolongó hacia la cabecera. En la iglesia de la Santísima Trinidad (segunda mitad del siglo XII) se conserva la cabecera del edificio anterior, que data de la primera mitad del siglo XII. La torre de San Millán formaba parte del edificio previo, se construyó en el siglo XI.

13 San Blas (1150-1250), San Justo (1150-1200), San Nicolás de Bari (1150-1200), San Pedro de los Picos (1100-1150), San Quirce (1100-1150), El Salvador (1150-1250), San Sebastián (1150-1250), Santa Eulalia (1150-1250), la Santísima Trinidad (1100-1250), Santo Tomás (1150-1250), San Andrés (11001250), San Clemente (1150-1250), San Juan de los Caballeros (1050-1250), San Marcos (1100-1200), San Millán (1120-1130), San Miguel Arcángel (1100-1150), la Veracruz (1200-1250), San Esteban (1150-1250), San Lorenzo (1050-1300) y San Martín (1100-1150). Ruiz Hernando, José Antonio, Rodríguez Montañés, José Manuel, García Guinea, Miguel Ángel y Pérez González, José María. Enciclopedia del románico en Castilla y León. Segovia. Tomo III. Aguilar de Campoo: Fundación Santa María la Real, 2007. 
IDENTIDAD Y DIMENSIÓN SOCIAL DE LA CONSTRUCCIÓN PLENOMEDIEVAL ECLESIÁSTICA

pocos casos el inicio de la construcción data de la centuria anterior ${ }^{14}$. En buena parte de las iglesias el proceso constructivo se dilató hasta el siglo XIII, ampliando algunos espacios o realizando reformas en el edificio existente ${ }^{15}$. Estos datos nos permiten imaginar el pulso de la ciudad medieval en el periodo entre ambas centurias, con buena parte de sus iglesias en construcción, donde el ir y venir de grupos de artesanos, de carretas con trasporte de material e incluso de hornos para fabricar cal y ladrillo, nos ofrecen una imagen extraordinariamente dinámica de la población.

Por otro lado, Sepúlveda se asienta sobre un macizo rocoso de caliza, horadado a su alrededor por las hoces del Duratón y del Caslilla, que le proporcionaban protección natural frente a posibles invasores. La villa contaba en el siglo XIII con quince iglesias ${ }^{16}$, un número muy elevado para su tamaño, la mayor parte situadas intramuros ${ }^{17}$. Algunas de ellas han desaparecido ${ }^{18}$ (fig. 1). La mayoría de estos edificios data de principios del siglo XII, por tanto su construcción fue previa a la de las iglesias de Segovia ${ }^{19}$.

\section{Tipología ARQUiTECTÓNICA DE SUS IGLESIAS}

A partir de su análisis comparativo se pueden destacar ciertas características que dan forma al modelo arquitectónico medieval de ambas ciudades.

La tipología segoviana es una iglesia de nave única cuya cabecera, que destaca por su profundidad, se divide en dos cuerpos, el presbiterio cuadrangular y el ábside semicircular. Algunos edificios cuentan con dos ábsides al haberse añadido posteriormente

14 Los muros laterales de la cabecera de la iglesia de San Juan de los Caballeros se construyeron en el siglo XI.

15 La cronología de los edificios analizados en Segovia y Sepúlveda se ha tomado de la Enciclopedia del Románico, basada en el análisis de la iconografía de los elementos figurativos, así como documentos y epígrafes conservados, dependiendo de cada caso. El estudio que se presenta no propone una revisión de las fechas, puesto que no forma parte de sus objetivos. Además, aunque algunos elementos como la construcción de las bóvedas, sí permiten ajustar en mayor medida las fechas propuestas, la mayor parte de los sistemas constructivos analizados se utilizan en diferentes momentos de la historia, lo que no permite profundizar en esta cuestión. Tal y como ha propuesto uno de los revisores anónimos que ha valorado este texto, sería interesante revisar dichas cronologías acompañando el estudio que aquí se presenta con un análisis estratigráfico de las fábricas desde la arqueología de la arquitectura, que permitiría proponer las distintas fases constructivas en cada caso, de gran interés en las iglesias segovianas por la heterogeneidad de sus fábricas, profundizando así en la dinámica constructiva de estos edificios. Esperamos que estos resultados constituyan el inicio de nuevos análisis desde otras disciplinas.

16 Se han analizado las seis que se conservan: las iglesias de San Bartolomé, El Salvador, Nuestra señora de la Peńa, los Santos Justos y Pastor, Santiago y San Millán.

17 Con excepción de San Bartolomé, Santo Domingo y San Gil en el extremo este de la ciudad. Sainz Esteban, Alicia. Las murallas en las comunidades de villa y tierra de la diócesis de Segovia en los siglos XI a XIII. Técnica y sistemas constructivos de la arquitectura defensiva medieval. Tesis doctoral. Universidad de Valladolid, 2017.

18 Las iglesias de San Pedro, San Esteban y San Andrés. La iglesia de San Millán, en ruinas, está a punto de desaparecer, aunque sus restos han permitido incluirla en este análisis.

19 San Bartolomé (1100-1150), El Salvador (1050-1100), Nuestra Señora de la Peña (1100-1150), San Justo y Pastor (1100-1200), Santiago (1100-1200), San Millán (1100-1200), San Pedro (1200-1250), San Esteban (1200-1250) y San Andrés (1100-1200). Ruiz Hernando et alii, Enciclopedia III. 
IDENTIDAD Y DIMENSIÓN SOCIAL DE LA CONSTRUCCIÓN PLENOMEDIEVAL ECLESIÁSTICA EN SEGOVIA Y SEPÚLVEDA ENTRE LOS SIGLOS XI Y XIII: SIMILITUDES Y DIVERGENCIAS ROCÍO MAIRA VIDAL

otro cuerpo semicircular precedido de presbiterio, adosados al muro sur de la cabecera ${ }^{20}$. La iglesia de San Lorenzo, de una sola nave, tiene cabecera tripartita. Se trata de un caso excepcional cuya nave formaba parte de la iglesia anterior mientras que la cabecera se construyó con posterioridad ${ }^{21}$. Once de las veinte iglesias segovianas siguen la tipología indicada ${ }^{22}$. Únicamente seis iglesias cuentan con tres naves y cabecera tripartita ${ }^{23}$. Se trata de edificios de mucha entidad, la mayor parte de ellos situados intramuros. Sólo en dos ejemplos encontramos una tipología extraña, con dos naves, la central y la lateral norte ${ }^{24}$, aunque podrían ser fruto de un proyecto inacabado o de reformas posteriores. Antonio Ruiz llama la atención sobre estos casos, que contaban con una nave lateral adosada a la nave central, sin cabecera y cuyo lado oriental entestaba contra la torre, construidos entre finales del siglo XII y principios del XIII. En origen permanecían autónomos a la iglesia y posteriormente se incorporaban a ésta abriendo el muro con una serie de arcos formeros. Se desconoce el uso que tendría este espacio y el autor aclara que no estaría relacionado con la ampliación de la iglesia, ya que en origen estaban cerrados. Ruiz Hernando afirma que esta solución se ejecutó en la nave lateral norte de El Salvador, en San Nicolás de Bari y San Quirce, en ambos casos desaparecida, y posiblemente se intentó llevar a cabo en San Juan de los Caballeros. La disposición exterior de ambos cuerpos, estrechos y alargados, uno longitudinal y el otro vertical, daría lugar a una volumetría global de proporciones extrañas ${ }^{25}$. Por último, habría que destacar la iglesia de la Veracruz, de planta dodecagonal y cuatro ábsides, ejemplo único en Castilla que queda fuera de la clasificación tipológica.

Las iglesias de Sepúlveda, con excepción de San Justo y Pastor, son de nave única. Su cabecera está compuesta por un ábside semicircular y presbiterio recto. Contrariamente a lo que ocurre en Segovia, el espacio de la cabecera resulta demasiado breve como consecuencia del desarrollo longitudinal extraordinariamente corto del presbiterio ${ }^{26}$. Las iglesias de San Millán y San Pedro, con cabecera de testero plano cubierta con bóveda de cañón, no seguían el esquema mencionado. El coste invertido en la construcción de este tipo de cabecera era notablemente menor respecto de aquellas con ábside semicircular abovedado en sillería. Aunque la solución de cabecera semicircular estaba muy extendida en la primera mitad de la Plena Edad Media, su construcción no era sencilla y conllevaba un elevado coste, tanto en medios auxiliares como en mano de obra especializada, fundamentalmente por la construcción de sus dos abovedamientos. La bóveda en vuelta de

\footnotetext{
20 Las iglesias de San Andrés, San Blas y San Clemente.

21 Ambas fases se distinguen gracias al grosor de los muros y a la distinta inclinación de las dos partes de la iglesia.

${ }_{22}$ Las iglesias de San Andrés, San Blas, San Clemente, San Justo, San Lorenzo, San Marcos, San Pedro de los Picos, San Quirce, San Sebastián, la Santísima Trinidad y Santo Tomás.

23 Las iglesias de San Esteban, San Juan de los Caballeros, San Martín, San Miguel Arcángel, San Millán y Santa Eulalia.

24 El Salvador y San Nicolás de Bari.

25 Ruiz Hernando, José Antonio. «La arquitectura medieval en Segovia». En Segovia 1088-1988. Congreso de historia de la ciudad. Actas. Segovia: Junta de Castilla y León, 1991, pp. 145-149.

26 Esta característica la encontramos en las iglesias de El Salvador, Nuestra Señora de la Peńa y San Millán.
} 
IDENTIDAD Y DIMENSIÓN SOCIAL DE LA CONSTRUCCIÓN PLENOMEDIEVAL ECLESIÁSTICA

horno presenta cierta complejidad si su ejecución se lleva a cabo en sillería. La talla de la cara de intradós de cada dovela viene definida por la curvatura del cuarto de esfera, y por tanto es distinta en cada hilada respecto de las sucesivas. Las dovelas de una misma hilada son iguales entre sí, pero diferentes respecto de las dovelas de otras hiladas. Esta particularidad requiere definir con precisión cada curvatura en el diseño previo y emplear distintas herramientas curvas para la talla de toda la bóveda. Son necesarias mano de obra especializada y una buena organización para evitar errores. Es el espacio más sagrado y representativo de la iglesia y como consecuencia es el lugar donde se hacía una inversión mayor $^{27}$. La bóveda de cañón que cubre el presbiterio no entrañaba tantas dificultades porque los sillares son todos iguales entre sí. Se trata de piezas prismáticas y no de dovelas curvas, por lo que el trabajo de talla requerido era más sencillo. En ambos casos se necesitan unas cimbras fuertes, robustas y estables para poder afrontar el enorme peso de estas estructuras. Era necesario cubrir con tablones de madera la superficie completa de la bóveda, al modo romano ${ }^{28}$, lo que encarecía mucho la obra y quizá ésta habría sido la razón para abovedar únicamente la cabecera en la mayor parte de los casos segovianos.

Hay un elemento propio de la arquitectura de Sepúlveda y que no encontramos en Segovia capital: las criptas bajo el presbiterio, que son espacios abovedados de piedra a los que se accede desde la nave. Las encontramos en tres iglesias sepulvedanas: El Salvador, Nuestra Seńora de la Peña ${ }^{29}$ y San Justo y Pastor $^{30}$.

\section{ELEMENTOS CONSTRUCTIVOS SINGULARES}

Se van a analizar y comparar los elementos constructivos más relevantes que conforman estos edificios y que pueden aportar información sobre los recursos y el coste invertidos acercándonos a la realidad social de ambas poblaciones.

\subsection{Torres, bóvedas y husillos}

La gran mayoría de las iglesias segovianas contaba con una torre situada junto a la cabecera (fig.2). La imagen de la ciudad amurallada debía ser imponente desde la lejanía, sobreelevada a los pies del Eresma y salpicada por las numerosas torres de las distintas iglesias de cada barrio. Estas torres daban cuenta de los diferentes núcleos que configuraban la población, y es probable que también funcionasen como elementos defensivos, no solo frente a posibles amenazas exteriores, sino también entre los distintos barrios de la ciudad, donde podían producirse disputas con graves consecuencias, tal y como

27 Maira Vidal, Rocío. «La estereotomía románica: trazas y cortes de cantería en la iglesia de San Juan de Rabanera». En Huerta, Santiago, Redondo Martínez, Esther, Gil Crespo, Ignacio Javier, y Fuentes, Paula (Eds.). Actas del Undécimo Congreso Nacional de Historia de la Construcción. Soria, 9-12 de octubre de 2019. Volumen II. Madrid: Instituto Juan de Herrera, 2019, pp. 645-654.

28 Choisy, Auguste. El arte de construir en Roma. Madrid: Instituto Juan de Herrera, 1999.

29 Las criptas de El Salvador y Nuestra Señora de la Peña están actualmente clausuradas.

30. Esta cripta ocupa el espacio bajo los ábsides central y norte. 
IDENTIDAD Y DIMENSIÓN SOCIAL DE LA CONSTRUCCIÓN PLENOMEDIEVAL ECLESIÁSTICA EN SEGOVIA Y SEPÚLVEDA ENTRE LOS SIGLOS XI Y XIII: SIMILITUDES Y DIVERGENCIAS ROCÍO MAIRA VIDAL

está documentado en otras ciudades medievales ${ }^{31}$. La puerta de ingreso se situaba en el presbiterio de la iglesia, quedando más protegida ${ }^{32}$. Estas torres presentan diferentes materiales y técnicas de ejecución entre los distintos cuerpos que se desarrollan en altura ${ }^{33}$, característica que se extiende a toda la fábrica de la iglesia en buena parte de los casos, presentando un aspecto heterogéneo al exterior (fig. 2).

En tres de las veinte iglesias segovianas o no se conserva su torre o no se conserva el edificio en su totalidad, por tanto su posición respecto al resto de la fábrica es desconoci$\mathrm{da}^{34}$. En aquellos casos en los que se conservan ambas estructuras encontramos el mismo número de iglesias con la torre adosada al muro septentrional de la cabecera ${ }^{35}$ respecto de aquellas en las que se sitúa adosada al meridional ${ }^{36}$, siete en ambos casos. Únicamente en tres iglesias la torre se sitúa sobre el crucero o la nave ${ }^{37}$. Entre las iglesias extramuros es mayoritaria la posición de la torre junto al muro norte de la cabecera, por el contrario, en las iglesias intramuros es más habitual adosada a su lado meridional.

Sepúlveda también era una ciudad torreada. Se trataba de una de las poblaciones más importantes de las Comunidades de Villa y Tierra en el siglo xI y principios del XII, y ciertamente su visión desde la lejanía mostraría su relevancia y poder económico. En Sepúlveda estas estructuras son más homogéneas que en Segovia, tanto en lo que respecta a su construcción como a su posición en el edificio. Se construyeron utilizando el mismo material y técnica en toda su altura (fig. 2). Se sitúan junto a la esquina nororiental de la nave, con dos excepciones; San Bartolomé, cuya torre es posterior y se encuentra en el lado sur de la fachada de poniente ${ }^{38}$ y la iglesia de los Santos Justo y Pastor, cuya torre, probablemente previa a la iglesia, se sitúa sobre el ábside sur. Una característica muy particular en algunos casos es su separación respecto de la iglesia. En El Salvador, San Millán y Nuestra Señora de la Peńa las torres son exentas y se comunican con la iglesia a través

31 Pamplona en época medieval estaba dividida en tres burgos: La Navarrería, San Cernin y San Nicolás. Las disputas entre ellos propiciaron la construcción del templo de San Saturnino en el barrio de San Cernin, de esta forma los feligreses podían cumplir con sus obligaciones religiosas ya que la catedral se encontraba en el burgo de Navarrería. En 1222 las luchas entre los burgos se habían recrudecido por lo que el rey Sancho el Fuerte y el obispo don Remigio de Navarra firmaron un documento para garantizar la paz en el que se prohibía al burgo de San Nicolás construir más fortificaciones contra el burgo de San Cernin, autorizando a los habitantes de San Cernin a demoler la llamada torre de la sal del barrio de Navarrería y con este material reparar sus propias fortificaciones. Albizu y Sainz de Murieta, Juan. San Cernin. Reseña histórico-artística de la iglesia parroquial de San Saturnino de Pamplona. Pamplona: Editorial Aramburu, 1930, pp. 12-21.

32 Los accesos han sido modificados en la mayor parte de los casos.

33 El piso inferior es de mampostería en San Nicolás, de sillería en Santa Eulalia y de fábrica mixta San Justo.

${ }_{34}$ Se trata de las iglesias de San Blas (no quedan vestigios de torre), San Miguel Arcángel (desaparecida, aunque se han localizado restos bajo la Plaza Mayor) y Santo Tomás (cuya torre es posterior, aunque podría asentarse sobre restos de la torre medieval).

35 San Justo, San Lorenzo, San Millán, San Nicolás de Bari, El Salvador, San Sebastián y Santa Eulalia.

36 San Andrés, San Esteban, San Juan de los Caballeros, San Marcos, San Pedro de los Picos, San Quirce y la Veracruz.

37 Iglesias de San Clemente, San Martín y Santísima Trinidad.

38 Es probable que su torre original ocupase esta misma posición. La torre actual se realizó con sillares reutilizados de la fábrica anterior. 
de un pasadizo abovedado (fig. 2). Se podría pensar que la torre se llevó a cabo en un momento distinto respecto de la iglesia, sin embargo, se trata de estructuras coetáneas. No se accede a ellas desde el exterior de forma independiente a la iglesia ${ }^{39}$ sino a través del muro norte de la nave. Son pasos discretos y estrechos, con dimensiones adecuadas para pasar de uno en uno. Este tipo de acceso y la opacidad de los lienzos del cuerpo inferior hacen pensar en un uso defensivo. Su situación en una zona fronteriza en el siglo XI aconsejaría disponer de estructuras capaces de albergar a la población de cada barrio, dificultando el acceso del enemigo. Sin embargo, este cometido era propio de la muralla, que junto con la orografía del lugar preservarían el acceso a la ciudad. Podrían haber funcionado como torre vigía, en cuyo caso no sería necesario contar con una torre por iglesia, habida cuenta el elevado coste de su construcción. Además, presentan estructuras abovedadas en los niveles superior e inferior que ayudan a estabilizar los lienzos y a protegerla frente a la propagación del fuego en caso de producirse un incendio en los forjados de madera intermedios. ¿Se trataría entonces de un elemento representativo de la ciudad o de los núcleos poblacionales que las formaban?
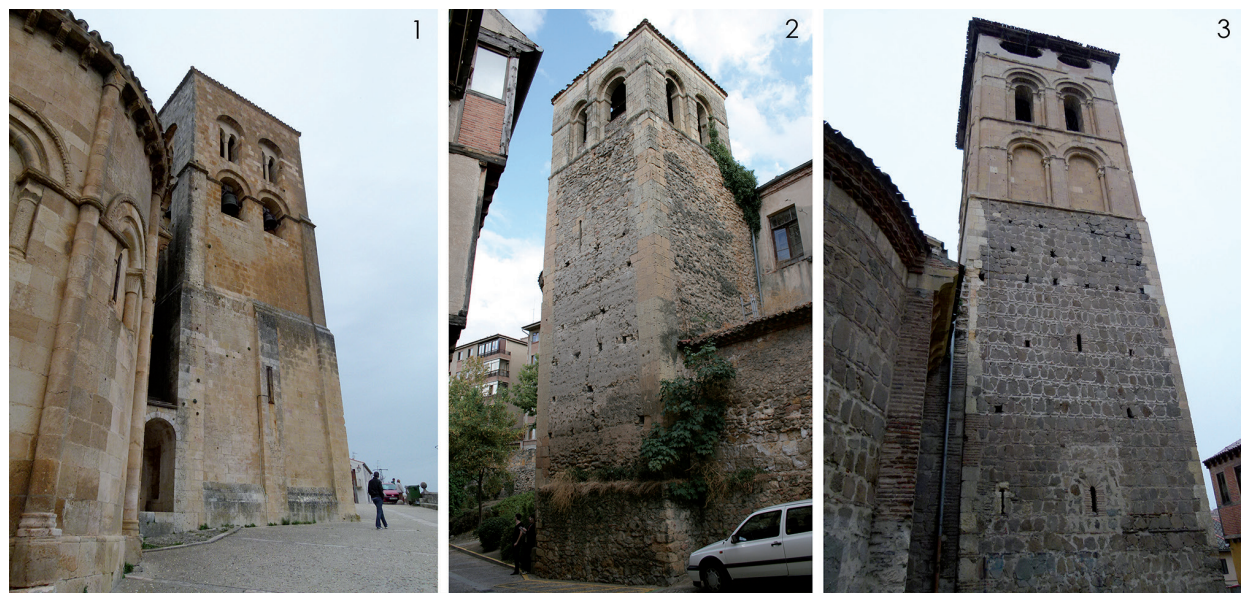

Figura 2. Torres de las iglesias de: 1. El Salvador (Sepúlveda), 2. San Nicolás de Bari (Segovia) y 3. San Justo (Segovia). Fotografías de la autora.

Su aspecto recio y defensivo debió jugar también un papel importante formando parte de la imagen representativa de poder. En Segovia la mayor parte de sus torres se construyeron, junto con los pórticos, con posterioridad a la iglesia ${ }^{40}$. Por contra en

39 Esto ocurre en las torres de La Moraña. Merino Gómez, Elena. Torres medievales en la Baja Moraña (Ávila): análisis constructivo, histórico y artístico a partir de su documentación gráfica. Tesis doctoral. Universidad de Valladolid, 2011.

40 Con excepción de San Sebastián, cuya torre se levantó junto con la cabecera, y San Millán, donde la iglesia es posterior a la torre, el resto datan en su mayoría de la segunda mitad del siglo XII y son posteriores a la construcción de la iglesia. Se ejecutaron en la misma fase que los pórticos. Ruiz Hernando, «La arquitectura», pp. 127-172. 
Sepúlveda son coetáneas. Esta particularidad es relevante ya que se trata de un elemento simbólico de coste elevado. Los muros deben tener un grosor suficiente para que la estructura resulte estable a pesar de su altura. Su elevación requiere andamios, grúas y poleas de mayor altura, lo que encarece la construcción. Además, los abovedamientos son estructuras costosas. Quizá la ejecución tardía de las torres de Segovia esté relacionada con el incremento de su posición de poder a partir de finales del siglo XII, momento en que se constituye como la población más importante de las Comunidades de Villa y Tie$\mathrm{rra}^{41}$, lo que aconsejó construir elementos representativos de la modificación de su estatus al final de la centuria. Parece menos probable que se construyesen por motivos defensivos respecto a una amenaza exterior, aunque podrían tener su origen en disputas internas o elementos simbólicos entre los mismos pobladores de la villa ${ }^{42}$.

Las torres segovianas constituyen un elemento arquitectónico singular porque albergan buena parte de las bóvedas de crucería realizadas en esta cronología ${ }^{43}$. La construcción de este tipo de abovedamiento exige un mayor conocimiento de las estructuras de fábrica y una mayor destreza en su montaje y ejecución, sin embargo, constituyen estructuras de menor coste al abaratar la mano de obra de cantería y simplificar los medios auxiliares, reduciendo los tiempos de ejecución. La construcción de bóvedas de crucería es muy escasa en la ciudad, podemos encontrarlas en las torres de San Justo y El Salvador, así como cubriendo alguno de los presbiterios laterales que anteceden al ábside únicamente en cuatro de las iglesias: en San Clemente y San Quirce en el presbiterio sur y en San Juan de los Caballeros y San Esteban en el presbiterio norte. En el resto de edificios las bóvedas utilizadas en las torres son masivas, propias de la primera mitad de la Plena Edad Media, como bóvedas de arista, bóvedas baídas, cúpulas ochavadas y bóvedas de cañón ${ }^{44}$. En la tipología segoviana los abovedamientos se reservaban para el espacio inferior de las torres ${ }^{45}$. Los cuerpos superiores se remataban con armaduras de madera ${ }^{46}$, con excepción de San Millán, cuya bóveda se sitúa en el cuerpo elevado. Quizá por ello la mayor parte de estas bóvedas se construyeron en sillería al ser más accesibles, con excepción de la mencionada San Millán, cuya torre, previa a la ejecución de la iglesia y datada

41 Como consecuencia de la restauración medieval del Obispado de Segovia.

42 El conocimiento de los promotores de estas torres (y por tanto de las iglesias) aportaría nuevos datos de especial interés en relación con su posible naturaleza defensiva, tal y como ha sugerido uno de los revisores anónimos de este texto.

43 Antonio Ruiz destaca que casi todas las torres segovianas se construyeron después de la iglesia, siendo coetáneas con la ejecución del pórtico. Además, apunta que en origen las iglesias segovianas contarían únicamente con espadaña, como la que aún se conserva en la iglesia de Santo Tomás. Ruiz Hernando, José Antonio. «La arquitectura», pp. 127-172.

44 En las torres de las iglesias de San Juan y Santo Tomás son bóvedas de arista, en San Nicolás y El Salvador son de cañón y en San Millán es una bóveda baída. En San Esteban la cúpula ochavada ha sido rehecha posteriormente. Ruiz Hernando, José Antonio. «El románico en Segovia». En Enciclopedia del románico en Castilla y León. Segovia. Tomo I. Aguilar de Campoo: Fundación Santa María la Real, 2007, pp. 49-88.

45 Ruiz Hernando, «La arquitectura», pp. 127-172.

46 Cuatro de las torres no conservan original el piso superior: San Justo, San Sebastián, Santa Eulalia y San Clemente. 
IDENTIDAD Y DIMENSIÓN SOCIAL DE LA CONSTRUCCIÓN PLENOMEDIEVAL ECLESIÁSTICA

a finales del siglo $\mathrm{xI}^{47}$, cuenta con una bóveda baída de calicanto encofrada sobre arcos $\operatorname{cruzados}^{48}$, tipología diferente a la que encontramos en las torres de Sepúlveda, donde además los arcos cruzados arrancan desde el centro de cada lienzo, contrariamente a lo que ocurre en San Millán, donde se sitúan en las esquinas de los muros de la torre.

En Sepúlveda tres de las cinco torres conservadas cuentan con dos espacios abovedados ${ }^{49}$, en el nivel inferior y el superior. Las bóvedas del cuerpo inferior son de cañón mientras que las del superior son en su mayoría bóvedas esquifadas, dos de ellas sobre arcos cruzados. Las bóvedas de cańón de El Salvador y Nuestra Señora de la Peńa se ejecutaron en sillería, quizá por encontrarse en espacios más accesibles, mientras que en San Millán la inferior es de mampostería y la superior es encofrada ${ }^{50}$. Las bóvedas esquifadas de Nuestra Seńora de la Peña ${ }^{51}$, El Salvador y Santiago se ejecutaron con mampostería, mientras que la de San Justo y Pastor es encofrada de calicanto.

Se puede concluir que las tipologías de abovedamientos utilizados en cada caso responden a su cronología. Mientras en Sepúlveda los abovedamientos son típicos de la primera mitad de la Plena Edad Media, en Segovia comienzan a presentar soluciones propias de la segunda mitad, con mayores conocimientos en su funcionamiento estructural y un mayor aprovechamiento de los recursos. Por otro lado, las bóvedas sin arcos, tanto las de cañón como las esquifadas, requieren cuajar de tablones toda la superficie abovedada, lo que complica y encarece la construcción. Si además son de sillería, requieren la participación de varias cuadrillas de canteros especializados. Las bóvedas con arcos y de mampostería o encofradas requieren menos recursos. El material no necesita mano de obra especializada y los arcos permiten simplificar las cimbras utilizadas al funcionar como estructuras auxiliares permanentes. Quizá por ello este tipo de bóvedas se reservó para las partes altas, espacios que rara vez se ven y que permitían ejecutar abovedamientos más rápidos, con una técnica constructiva más económica.

El husillo, que daba acceso a los distintos niveles de la torre, es un elemento singular que en Segovia solía construirse o bien completamente embutido en el grosor de los muros ${ }^{52}$ o bien semiembutido presentando parte del desarrollo de la escalera adosada hacia el interior o el exterior de la torre ${ }^{53}$. Al aprovechar parte del grosor del muro para

47 Merino de Cáceres, José Miguel. «La torre de la iglesia de San Millán en Segovia». En Huerta Fernández, Santiago (ed.). Actas del Cuarto Congreso Nacional de Historia de la Construcción. Cádiz, 27-29 de enero de 2005. Madrid: Instituto Juan de Herrera, 2005, pp. 771-779.

48 En Segovia hay otra bóveda sobre arcos cruzados ejecutada con mampostería, en el espacio superior del edículo de la iglesia de la Veracruz. El crucero de San Millán se realizó con ladrillo. El crucero de San Martín debe contar con una solución similar al crucero de San Millán, pero las vestiduras barrocas que la tapan no permiten corroborar esta hipótesis. Fuentes González, Paula. Bóvedas de arcos entrecruzados entre los siglos X y XVI. Geometría, construcción y estabilidad. Tesis doctoral. Universidad Politécnica de Madrid, 2013.

49 El Salvador, Nuestra Señora de la Peńa y San Millán.

50 Únicamente se conservan los arranques de las esquinas, a punto de desaparecer.

51 Muy deteriorada, en riesgo extremo de desplome si no se toman medidas pronto.

52 Como en las iglesias de San Martín, Santa Eulalia, Santo Tomás y la Veracruz.

53 En San Esteban y San Justo la escalera se desarrolla hacia el interior perforando las bóvedas. En San Quirce, El Salvador y la Santísima Trinidad se trata de un volumen adosado hacia el exterior. En San Clemente y San Juan de los Caballeros están embutidas en un contrafuerte de la torre. En San Nicolás de Bari su posición únicamente se delata por la disposición de saeteras en altura. 
albergar esta estructura se ejecutaban en el mismo momento que la torre, utilizando el husillo como medio auxiliar para llevar a cabo la construcción de las partes altas. De esta forma se reducía o eliminaba el volumen hacia el exterior, quedando más protegida y abaratando el coste respecto de la construcción de una estructura independiente adosada al muro. Su ejecución en sillería elevaba su coste, sin embargo era la solución más habitual y también la más segura para fines defensivos ${ }^{54}$. En Sepúlveda la mayor parte de las torres no cuentan con husillos sino con escaleras de madera. Únicamente en tres iglesias, San Millán, San Justo y Pastor y Nuestra Señora de la Peña, parte de la escalera se desarrolla embutida en el muro, en los dos primeros casos en el lienzo que separa la torre y el ábside.

\subsection{Pórticos y portadas}

Los pórticos constituyen uno de los elementos principales de la arquitectura medieval de Segovia. Su posición más habitual es la orientación sur ${ }^{55}$, aunque algunas iglesias cuentan también con pórticos en sus fachadas norte y oeste ${ }^{56}$ o al menos en una de las $\operatorname{dos}^{57}$. Únicamente las iglesias de San Marcos y la Veracruz, ésta última por su particular tipología, no cuentan con este tipo de estructuras abiertas al exterior. Los pórticos debían jugar un papel importante en la vida de la ciudad, puesto que es uno de los elementos del edificio donde se emplearon recursos de mayor coste: material de mejor calidad, cuadrillas de canteros especializados al estar ejecutados con sillería bien escuadrada y escultores para realizar las representaciones iconográficas en sus capiteles ${ }^{58}$. Se cubrían con armaduras de madera, más sencillas y con un coste menor que si se tratase de abovedamientos, como por el contrario ocurre en los nártex. Salgado Pantoja relaciona la ubicación de los pórticos con la fachada de mayor carácter monumental de la iglesia, orientada hacia una plaza importante, ya que relaciona su uso con funciones seglares, como asamblearias (lugar de reunión del concejo), mercadillos o lonjas, para uso judicial o incluso como espacio de reunión y de juegos para la población ${ }^{59}$. Podían tener otras funciones, como funeraria o acogida de personas huidas de la justicia e incluso la de aunar el uso religioso

54 Las iglesias de San Andrés, San Blas, San Lorenzo, San Marcos, San Millán, San Pedro de los Picos y San Sebastián cuentan con escaleras de madera en el espacio interior.

55 En San Sebastián, El Salvador, Santísima Trinidad y Santo Tomás aún se conserva. En San Blas, San Clemente y San Nicolás de Bari ha desaparecido o se ha rehecho. En San Justo y San Quirce no se ha podido confirmar, pero es la hipótesis más probable.

56 En San Esteban, San Martín y Santa Eulalia.

57 San Andrés y San Millán contaban con pórticos en sus fachadas sur y norte. En las excavaciones arqueológicas de San Miguel Arcángel únicamente se ha podido confirmar la existencia del pórtico norte. Las iglesias de San Juan de los Caballeros y San Lorenzo contaban con pórticos en sus fachadas norte y oeste.

58 Salgado Pantoja opina que su construcción debía ser iniciativa de los habitantes de la ciudad. Salgado Pantoja, José Arturo. Pórticos románicos en las tierras de Castilla. Aguilar de Campoo: Fundación Santa María la Real, 2014.

59 En la Edad Moderna estas actividades cambiaron de lugar de celebración al construirse edificios destinados a estos usos, tapiándose los pórticos y convirtiéndolos en naves secundarias. Salgado Pantoja, Pórticos. 
IDENTIDAD Y DIMENSIÓN SOCIAL DE LA CONSTRUCCIÓN PLENOMEDIEVAL ECLESIÁSTICA

y el laico al funcionar como espacio para oír misa para aquellos que no podían acceder a su interior, como catecúmenos o penitentes y para la celebración de procesiones.

El pórtico parece tener su origen en la iglesia de El Salvador de Sepúlveda ${ }^{60}$. No sabemos con exactitud en qué momento aparece en Segovia ${ }^{61}$, pero es en esta ciudad donde más se extiende su uso hasta llegar a convertirse en una característica de su tipología eclesiástica. Según Ruiz, la construcción del pórtico segoviano se llevaba a cabo en las orientaciones del edificio que contaban con portada ${ }^{62}$. Salgado Pantoja relaciona la existencia de varios pórticos con la cantidad de población de la ciudad y afirma que debían construirse en una segunda fase tras la ejecución de la iglesia, y de forma consecutiva, no a la vez.

En Sepúlveda, el pórtico también constituye un elemento característico de sus iglesias, si bien su uso no se extendió tanto como en Segovia, ocupando únicamente una de las fachadas, la meridional. Hay dos excepciones; por un lado, la iglesia de San Bartolomé, que como consecuencia de la pronunciada pendiente del terreno en su lado sur presenta el pórtico en la orientación opuesta. Por otro lado, la iglesia de San Justo y Pastor, que cuenta con pórtico en sus orientaciones sur y oeste.

La mayor parte de las iglesias contaban con varias portadas. Aquellas con tres pórticos, como San Martín, San Esteban y Santa Eulalia, presentaban también tres portadas. En otros casos, como San Millán, sólo hay constancia de dos pórticos, sur y norte, sin embargo, conserva sus portadas meridional y occidental, lo que hace pensar que contaría con otra en la orientación norte que daría paso al pórtico, e incluso se especula con la idea de haber contado con un nártex en la fachada oeste. No es posible determinar el número de portadas de las que solían disponer estas iglesias o incluso su orientación habitual, puesto que se trata de uno de los elementos más transformados en épocas posteriores ${ }^{63}$.

En San Juan de los Caballeros y San Martín, la portada oeste va precedida de un nártex, aunque no suele ser habitual en la arquitectura segoviana. Este volumen saliente se trata nuevamente de una estructura que acarreaba un importante sobrecoste, ya que son cuerpos realizados en sillería, con escultura, y además cubiertos por bóveda de crucería. Su orientación oeste enfatiza este acceso y la direccionalidad del edificio.

El único nártex entre las iglesias sepulvedanas es el de Nuestra Señora de la Peña, realizado en sillería, con bóveda de crucería e integrado en el pórtico sur frente a la portada.

60 Ruiz Hernando, «La arquitectura», pp. 127-172.

${ }_{61}$ Ruiz opina que el primer pórtico de la ciudad es el de la fachada norte de la iglesia de San Millán. Los siguientes pórticos habrían sido San Lorenzo, San Juan de los Caballeros y San Martín. Posteriormente la Santísima Trinidad, San Clemente, Santa Eulalia, San Andrés, San Quirce y San Blas con soluciones más sencillas.

62 Ruiz Hernando, «La arquitectura», pp. 142-145.

63 Algunas iglesias cuentan únicamente con una portada: San Andrés y El Salvador al sur, San Juan de los Caballeros al oeste, y San Pedro de los Picos al norte. En el caso de San Clemente, San Justo, San Lorenzo, Santísima Trinidad y Veracruz las portadas se sitúan en las fachadas occidental y meridional, mientras que en San Marcos y Santo Tomás se sitúan en las orientaciones norte y sur. En las iglesias de San Blas, San Miguel Arcángel (desaparecida), San Nicolás de Bari, San Quirce o San Sebastián no se conservan las portadas medievales. 
IDENTIDAD Y DIMENSIÓN SOCIAL DE LA CONSTRUCCIÓN PLENOMEDIEVAL ECLESIÁSTICA EN SEGOVIA Y SEPÚLVEDA ENTRE LOS SIGLOS XI Y XIII: SIMILITUDES Y DIVERGENCIAS ROCÍO MAIRA VIDAL

\subsection{Los abovedamientos de la iglesia}

Uno de los elementos constructivos de mayor coste son los abovedamientos. Es difícil valorar este tipo de estructuras en Segovia, puesto que han sufrido importantes transformaciones en época barroca, sin embargo los datos de los que disponemos nos permiten afirmar que las bóvedas se reservaban fundamentalmente para la cabecera ${ }^{64}$, excepto en cuatro de los edificios, donde la nave también era un espacio abovedado: San Martín, Santa Eulalia, la Veracruz ${ }^{65}$ y la Santísima Trinidad ${ }^{66}$. En Sepúlveda, son comunes los abovedamientos de las naves en los edificios de mayor relevancia, como El Salvador y Nuestra Señora de la Peña. Quizá San Justo y Pastor contara con bóvedas en sus naves, sin embargo no se conservan restos que permitan afirmar esta hipótesis ${ }^{67}$. En las iglesias de Santiago ${ }^{68}$, San Millán y San Pedro, no se conserva la cubrición original, pero lo más probable es que se tratase de armaduras de madera, por las características de los muros y la ausencia de contrafuertes.

En ambas ciudades, se utilizaron las bóvedas de cañón en los abovedamientos del cuerpo de la iglesia. En Segovia, encontramos además otra tipología para resolver el espacio central del crucero ${ }^{69}$, las bóvedas de $\operatorname{arcos}$ cruzados sobre trompas ${ }^{70}$, que constituyen una solución más compleja a nivel geométrico y constructivo. Tanto las iglesias de Segovia como de Sepúlveda recurren a los abovedamientos característicos de los siglos XI y XII en la solución de su cabecera: ábside cubierto con bóveda en vuelta de horno y presbiterio con bóveda de cañón semicircular ${ }^{71}$. Dos de las iglesias sepulvedanas, San Millán y San Pedro, contaban con cabecera de testero plano cubierta por bóveda de cañón,

64 Las iglesias de San Andrés, San Clemente, San Juan de los Caballeros, San Justo, San Lorenzo, San Miguel Arcángel, San Millán, San Pedro de los Picos, San Quirce y Santo Tomás. En San Andrés y San Millán se conservan las cubiertas de madera total o parcialmente, sin embargo, en la mayoría se trata de hipótesis por la escasa anchura de sus muros, insuficiente para hacer frente a los empujes de las bóvedas, o por la ausencia de contrafuertes.

65 La iglesia de la Veracruz presenta abovedamientos particulares por la peculiaridad de su tipología, como la bóveda de cañón anular que cubre el espacio circular entorno al edículo.

${ }_{66}$ En la iglesia de San Millán, probablemente la nave se diseñó como un espacio abovedado, sin embargo, acabó cubriéndose con armadura de par en hilera con dobles tirantes y cuadrales en las esquinas. Se conservan algunas de sus piezas. Aunque los muros cuentan con apeos suficientes para las bóvedas, según Santiago Huerta ni su robustez ni la proporción del espacio eran adecuadas para voltearlas. Ruiz Hernando et alii, Enciclopedia III.

${ }_{67}$ La armadura actual no es original. Los muros de la nave parecen pertenecer a un templo anterior siendo la apertura de sus formeros fruto de una reforma posterior.

68 El cuerpo lateral adosado al costado norte de la nave, probablemente anterior a la iglesia, está abovedado con cañón de mampostería sobre arcos fajones de sillería. La galería que lo conecta con la nave también está abovedada.

69 Las iglesias de Sepúlveda no disponen de crucero.

70 En el crucero de San Clemente, situado bajo la torre, parece haber una bóveda angevina o aquitana oculta tras los revocos barrocos, tal como indica el gran peralte de la estructura. Son bóvedas herederas de la construcción bizantina, poco usuales en la Península Ibérica, que se desarrollaron en el siglo XII en la zona occidental de Francia. Es posible que Pedro de Agen, primer prelado de Segovia, trajese consigo influencias ultrapirenaicas.

71 En San Clemente y San Quirce la bóveda de cañón es apuntada en vez de semicircular, disminuyendo el empuje horizontal y aumentando la estabilidad para los mismos grosores de muro. En Sepúlveda, cuyas 
IDENTIDAD Y DIMENSIÓN SOCIAL DE LA CONSTRUCCIÓN PLENOMEDIEVAL ECLESIÁSTICA

una solución más sencilla en cuanto a geometría y corte de la piedra ${ }^{72}$, aunque en ambos casos no supuso ninguna ventaja para el trabajo de cantería puesto que se ejecutaron con mampostería.

El sistema constructivo utilizado en las bóvedas podía elevar el coste de forma exponencial si se trataba de una técnica especializada, que además alargaba los tiempos de ejecución. La sillería habría sido la técnica más costosa entre los demás sistemas utilizados. En Segovia las bóvedas de las cabeceras ${ }^{73}$ de las iglesias de la Santísima Trinidad, San Millán, San Nicolás de Bari y San Juan de los Caballeros se ejecutaron en sillería ${ }^{74}$, sin embargo nos encontramos numerosos ejemplos donde el intradós de la cabecera está cubierto por enfoscados ${ }^{75}$, pinturas ${ }^{76}$ o vestiduras barrocas ${ }^{77}$ que impiden comprobar la técnica utilizada en sus abovedamientos. En algunos casos la sillería de la cara externa permite plantear que la hoja interior del muro y sus bóvedas son también de sillería. Se trata de las iglesias de San Lorenzo ${ }^{78}$, San Andrés ${ }^{79}$ y San Clemente ${ }^{80}$. En el resto de casos conservados, estas bóvedas se ejecutaron, casi con total seguridad, en mampostería. Al enumerar los datos expuestos y dando por válidas las hipótesis planteadas, nos encontramos que casi la mitad de los ejemplos segovianos contarían con bóvedas de sillería en la cabecera. En cuatro de estos ocho casos podemos confirmar que el presupuesto destinado a la construcción de este espacio, el más representativo de la iglesia, era notablemente mayor respecto al invertido en el resto del edificio, donde se utilizaron otras técnicas, con excepción de los pórticos. Por otro lado, las bóvedas del cuerpo de la iglesia presentan más variedad en los sistemas de ejecución utilizados. Al menos los abovedamientos de la nave de la Santísima Trinidad fueron construidos en sillería ${ }^{81}$. Por el contrario las bóvedas de cañón y de arista de las naves de San Martín y la bóveda de arcos cruzados del crucero de San Millán ${ }^{82}$,

iglesias datan de la transición entre los siglos XI y XII, no se utilizó la variante apuntada, probablemente por tratarse de una solución más habitual de la segunda mitad del siglo XII y primera del XIII.

72 Es una solución común en el ámbito rural y suele ser habitual hacia finales del siglo XII y principios del XIII.

73 La desparecida capilla mayor de San Martín, incluidas sus bóvedas, debieron haberse ejecutado en sillería teniendo en cuenta que los ábsides laterales presentan esta técnica.

74 En la torre de El Salvador, el ábside es de sillería y su bóveda de ladrillo colocado de rosca.

75 Las bóvedas de la iglesia de la Veracruz, el ábside norte de la iglesia de San Juan de los Caballeros y los ábsides de San Marcos y San Quirce.

${ }^{76}$ La iglesia de San Justo y el ábside lateral de la iglesia de San Clemente (su muro exterior es de mampostería).

77 El ábside central de las iglesias de San Clemente, San Lorenzo, Santo Tomás y San Andrés.

78 Solo la cabecera y el pórtico se ejecutaron en sillería. La cabecera es posterior a la nave.

79 Solo el ábside central es de sillería, el lateral sur es de mampostería.

80 Únicamente el ábside central, el pórtico, el husillo y el hastial occidental se ejecutaron en sillería. El ábside sur es de mampostería.

${ }^{81}$ No es posible saber si las bóvedas de la iglesia de Santa Eulalia eran de sillería. Se reconstruyeron entre 1629 y 1631 , después del hundimiento de las originales.

82 El último restaurador del edificio, García Gil, afirmó que la plementería de esta bóveda «estaba construida en pie de ladrillo con grueso tendel». Paula Fuentes revela la existencia de varios quiebros pequeños en cada arco, lo que interpreta como resultado de haber utilizado cimbras que no eran enterizas. Considera que se construyeron dos plataformas de trabajo, una para realizar el muro octogonal y las trompas y la otra para situar las cimbras de los arcos y otros apoyos bajo las aristas de la superficie de plementería, entre los 
son de ladrillo. En otros ejemplos se utilizaron técnicas más económicas, como la mampostería. Es el caso de las bóvedas de la Veracruz ${ }^{83}$.

En Sepúlveda, en las iglesias de San Bartolomé, San Justo y Pastor, El Salvador y Nuestra Señora de la Peńa las bóvedas se ejecutaron con sillería, tanto en la cabecera como en la nave, siendo únicamente los dos últimos casos los que cuentan con bóvedas en el cuerpo de la iglesia. Por el contrario en la iglesia de Santiago la bóveda de horno es de mampostería y la de cañón de ladrillo a sardinel enfoscada ${ }^{84}$. En la iglesia de San Millán se utilizó mampostería de escaso tamaño, que además coincide con la cabecera de testero plano. La fotografía que se conserva de la iglesia de San Pedro no nos permite afirmar si la bóveda de la cabecera era de mampostería, en todo caso se trataría de la opción más probable teniendo en cuenta la factura del resto de las estructuras que formaban el edificio.

Las bóvedas de sillería tenían un coste muy elevado como consecuencia de la mano de obra especializada y de las dificultades que planteaba su montaje, especialmente por su gran tamaño. Se necesitaban grandes cimbras para sostenerlas hasta que entraban en carga, realizadas por carpinteros especializados, y grandes apeos para soportar los enormes empujes laterales. Ambos sistemas requerían una gran cantidad de madera para su fabricación. Quizá por ese motivo la mayor parte de las iglesias de Segovia cubren sus naves con armaduras de madera, que además posibilitan prescindir de los contrafuertes y reducir el grosor de los muros. En el caso de las bóvedas de ladrillo, era necesario habilitar hornos para su fabricación. La mano de obra era menos especializada, pero se necesitaba bastante cantidad de madera para calentar los hornos hasta la temperatura de cocción adecuada. Las bóvedas de mampostería requerían una menor especialización respecto de las dos técnicas anteriores, aunque se necesitaban importantes cantidades de cal. En estos dos últimos casos, los sistemas auxiliares requeridos para el montaje de las bóvedas eran igualmente importantes.

Segovia contaba con excelentes bosques de pino muy cercanos, en Valsaín, El Espinar y Navafría. En Valsaín crecían hayas, robles y sobretodo pinos ${ }^{85}$. En el entorno de la ciudad, había otras especies de vegetación disponibles, como sabinas, fresnos, chopos, sauces y encinas, sin embargo, este tipo de árboles no sirven para la construcción de grandes edificios porque no alcanzan importantes alturas que permitan utilizarlos en la fabricación de vigas que cubren grandes luces. Por el contrario, resultaban idóneos para la ejecución de los medios auxiliares, como andamios, grúas o poleas, que normalmente no requerían grandes escuadrías. Sepúlveda no contaba con la presencia de importantes bosques cercanos, sino con sabinas y vegetación propia de ribera al situarse en las cercanías

que se dispuso una tablazón para abordar la ejecución de la plementería quedando los nervios parcialmente embutidos. Fuentes González, Bóvedas.

${ }^{83}$ Según Cabello y Dodero su plementería es un conglomerado de piedra enfoscada. Fuentes González, Bóvedas.

84 Ruiz Hernando et alii, Enciclopedia III.

85 Valsaín fue propiedad de la ciudad y tierra de Segovia hasta finales del siglo XII, por lo que debió de constituir una de las fuentes principales de madera en la construcción de sus iglesias. Pasó a formar parte de las propiedades de la corona antes del cambio de centuria. Ruiz Hernando, "El románico en Segovia", p. 50 . 
IDENTIDAD Y DIMENSIÓN SOCIAL DE LA CONSTRUCCIÓN PLENOMEDIEVAL ECLESIÁSTICA

de las Hoces del Duratón. No son árboles de gran porte, pero sí serían adecuados para la ejecución de medios auxiliares. Sin embargo, la ciudad dispone de zonas de extracción de caliza prácticamente a pie de obra. Quizá la mayor cercanía de la piedra frente a la madera aconsejó a sus habitantes cubrir sus iglesias más importantes con abovedamientos ${ }^{86}$, ya que las escuadrías necesarias para las armaduras de madera serían considerables ${ }^{87}$.

Cabe destacar la solución utilizada en algunos ábsides laterales, en los cuerpos bajos de las torres y en los nártex de las iglesias segovianas, donde encontramos bóvedas de crucería cuatripartita $^{88}$ (fig. 3). Son estructuras más económicas, propias de la segunda mitad del siglo XII en adelante, y que requerían un mayor conocimiento del sistema constructivo por parte de los maestros. El trabajo de cantería necesario era menor en comparación con las soluciones tradicionales construidas a partir de la superficie de intradós, porque los nervios eran los únicos elementos que se ejecutaban en sillería. Cuentan con dos nervios cruceros y cuatro formeros embutidos en los muros ${ }^{89}$. La solución típica en el punto de confluencia de los dos nervios diagonales es la ausencia de clave: uno de los dos nervios es pasante y el otro muere contra él. De esta forma se evitaba la talla de la pieza de encuentro, la más complicada. En todo caso, en las iglesias de San Clemente y de San Juan de los Caballeros las bóvedas de crucería cuentan con clave (fig. 3), un sencillo volumen en forma de $\mathrm{cruz}^{90}$.

En Sepúlveda, únicamente encontramos una bóveda de crucería en el nártex de la iglesia de Nuestra Señora de la Peńa. En los ábsides laterales y los cuerpos bajos de las torres se utilizaron bóvedas de cañón. Otra estructura que dispone de nervios cruceros, además de las soluciones en los cuerpos altos de las torres, es la cripta de la iglesia de San Justo y Pastor (fig.3), sin embargo, no se trata de una estructura de crucería, ya que no funciona como tal. Es una bóveda de sillería de cañón a la que se le han añadido dos nervios decorativos que no están en contacto con su superficie de intradós ${ }^{91}$. Estas nervaduras debieron ejecutarse después de voltear la bóveda. La calidad de su estereotomía,

86 El rechazo o elección de la bóveda como cubrición de la iglesia respondería, según Ruiz Hernando, a cuestiones económicas y funcionales. Ruiz Hernando, José Antonio. La arquitectura de ladrillo en la provincia de Segovia siglos XII y XIII. Segovia: Excma. Diputación Provincial de Segovia, 1988, p. 32.

${ }_{87}$ Según Ruiz existen diferencias fundamentales entre ambas ciudades. En Segovia existía una continuidad de la tradición constructiva prerrománica con influencias hispanomusulmanas, que se ve reflejada en la utilización de armaduras como cubrición. La arquitectura sepulvedana surgió en un territorio sin condicionantes previos, donde se desarrollaron las bóvedas, solución netamente románica. Ruiz Hernando, La arquitectura, p. 25.

88 En el ábside sur de San Clemente y San Quirce, en el ábside norte de San Juan de los Caballeros y de San Esteban, en el cuerpo bajo de la torre de San Justo y El Salvador y en el nártex de San Martín y San Juan de los Caballeros. En el primer nivel de la torre de San Esteban hay una cúpula ochavada pero no es original, fue rehecha con posterioridad.

89 En algunos casos, la plementería entesta directamente en los lienzos de la iglesia, sin nervios de apoyo en este encuentro, como en San Clemente, donde no existe nervio formero norte.

90 El resto de bóvedas de crucería no se han podido ver; por tanto, no se ha incluido una descripción de los detalles de su estereotomía.

91 En el presbiterio de la iglesia de San Juan de Rabanera de Soria (1100-1150), encontramos la misma solución, una bóveda de cañón sobre dos nervios diagonales. Sin embargo, en este caso los nervios presentan su cara de trasdós oblicua, permitiendo el apoyo de la bóveda. Maira Vidal, «Estereotomía», pp. 645-654. 
con dovelas de gran longitud y talladas con curvatura, indican que se trata de un trabajo de alta especialización. La clave se ha resuelto en forma de cruz, pero en este caso, a diferencia de las claves segovianas, se trata de una pieza compleja por tener sus brazos curvos, que requieren la utilización de herramientas de talla distintas, como el baivel.
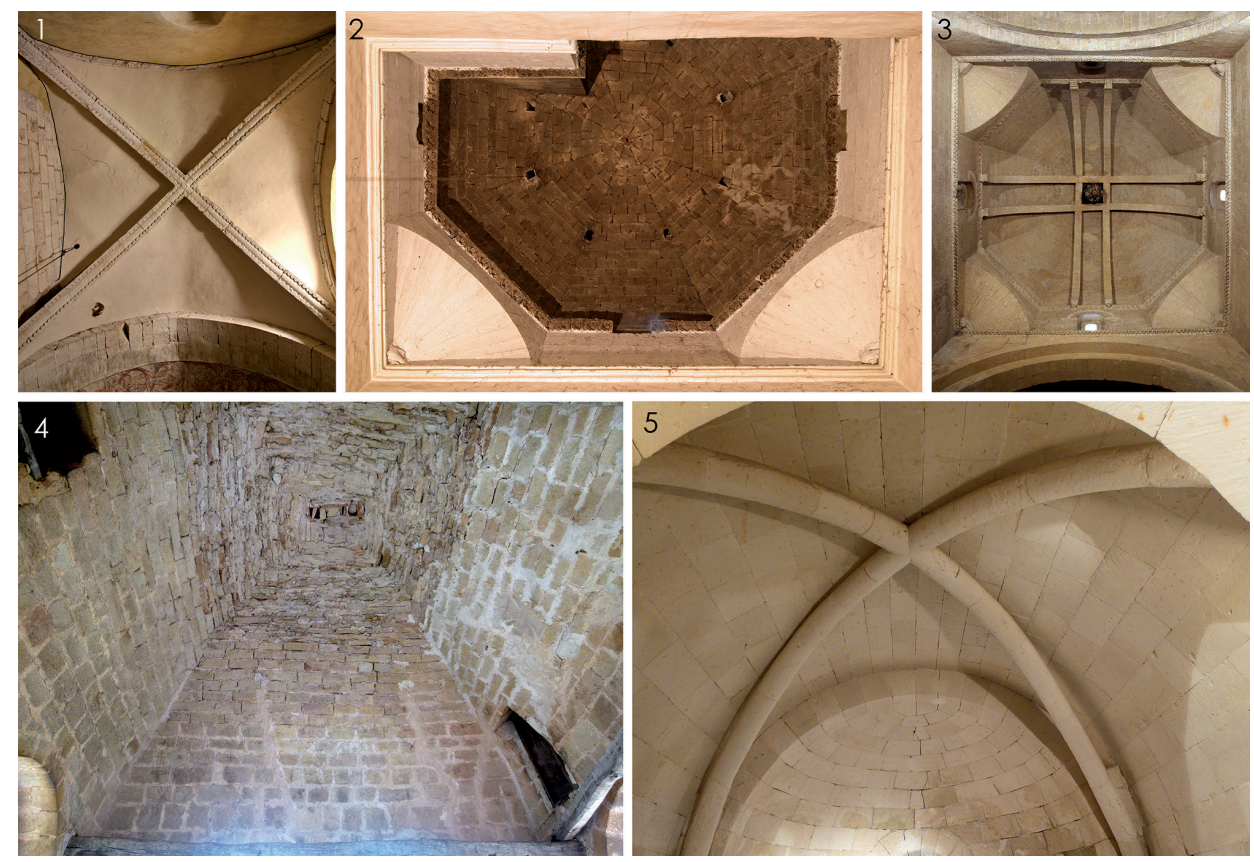

Figura 3. 1. Bóveda de crucería en el ábside sur de San Clemente (Segovia); 2. Cúpula ochavada en la torre de San Esteban (Segovia); 3. Bóveda de arcos cruzados en el crucero de San Millán (Segovia); 4. Bóveda esquifada en la torre de Nuestra Señora de la Peńa (Sepúlveda); 5. Bóveda de crucería en la cripta de la iglesia de los Santos Justo y Pastor (Sepúlveda). 1, 2 y 3 fotografías de la Enciclopedia del Románico. 3 y 4 fotografías de la autora.

Las bóvedas segovianas sobre arcos cruzados, presentes en el crucero y el cuerpo superior de la torre de San Millán (fig. 3), el cuerpo superior del edículo de la Veracruz y probablemente en el crucero de San Martín, no se pueden considerar bóvedas de crucería a pesar de contar con nervaduras. Las bóvedas de crucería se diseñan a partir de la geometría de los nervios ${ }^{92}$, mientras que las bóvedas románicas se trazan definiendo la forma de su superficie ${ }^{93}$. Estas bóvedas de arcos cruzados son estructuras configuradas desde la

92 Son los nervios los que tienen una geometría conocida, normalmente arcos semicirculares o apuntados. La plementería que se dispone entre ellos es una superficie sin geometría definida, donde las hiladas de mampuestos se van colocando hasta cerrar la superficie. Palacios Gonzalo, José Carlos. La Cantería Medieval. La construcción de la bóveda gótica española. Madrid: Editorial Munilla-Lería, 2009.

93 Las bóvedas románicas se caracterizan por la geometría de su superficie. Las de cañón son medios cilindros, mientras que las de horno son cuartos de esfera. En los cruceros son cúpulas sobre troncos de cono. 
geometría de su superficie ${ }^{94}$, con arcos añadidos que permitirían controlar su diseño durante la ejecución y trabajarían como refuerzo permanente para la bóveda funcionando también como apoyo para los tablones de madera de las cimbras. Ocurre lo mismo con las bóvedas de arcos cruzados de las torres sepulvedanas, aunque en este caso su geometría es diferente, en rincón de claustro o también llamadas esquifadas (fig. 4), cuya superficie se define a partir de la intersección de dos bóvedas de cañón. Las bóvedas del nivel superior de las torres de El Salvador y San Justo y Pastor se apoyan sobre arcos diagonales, sin embargo, las de Nuestra Señora de la Peña (fig.3) y Santiago se construyeron sin arcos, lo que repercutió en un mayor coste de ejecución (fig.4).
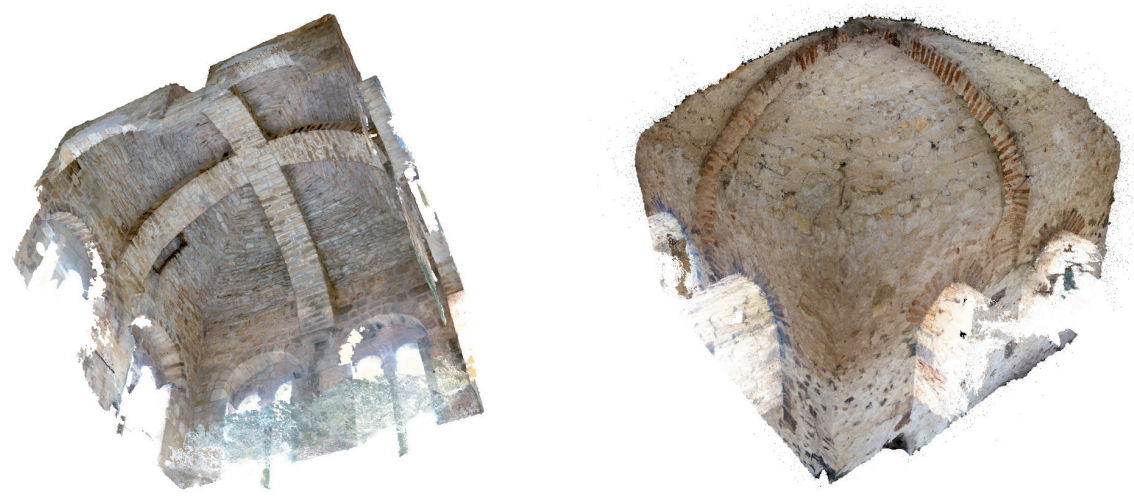

Figura 4. Modelos fotogramétricos realizados por la autora de las bóvedas esquifadas en el cuerpo superior de las torres de El Salvador (izquierda) y los Santos Justo y Pastor (derecha) de Sepúlveda.

Las superficies de plementería de estas bóvedas se realizaban con dos técnicas: en algunos casos son de mampostería y en otros encofrados de calicanto ${ }^{95}$. Ambos sistemas requerían un fuerte entablonado de madera que sujetase la argamasa de mampuestos y cal hasta su fraguado. Para ello eran necesarias fuertes cimbras a la romana ${ }^{96}$, con importantes cantidades de madera. Las bóvedas de crucería, cuyas superficies de plementería se ejecutaban con sillarejos de tamaño medio, eran estructuras más económicas. El único caso entre los estudiados es el nártex de la iglesia de Nuestra Señora de la Peña. Este tipo de superficie no precisa construir un entablonado completo para la construcción de la bóveda, sería suficiente con disponer de dos cimbras para sus nervios y algunos apoyos puntuales en cada hilada de plementos. De esta forma se podían simplificar los medios

94 La bóveda del crucero de San Millán es una cúpula poligonal de ocho paños con dobles arcos cruzados, quizá la misma solución que en San Martín, mientras que la que remata su torre es una bóveda baída sobre dos arcos diagonales (una cúpula seccionada por cuatro planos verticales que forman el cuadrado de la planta de la torre). La bóveda de la Veracruz es una cúpula sobre arcos cruzados.

95 Esta es la solución que se utilizó en la bóveda de la torre de San Millán de Segovia y la de San Justo y Pastor de Sepúlveda, donde han quedado huellas de los tablones de la cimbra. El resto de ejemplos se ejecutaron con mampostería.

96 Choisy, El arte. 


\section{IDENTIDAD Y DIMENSIÓN SOCIAL DE LA CONSTRUCCIÓN PLENOMEDIEVAL ECLESIÁSTICA EN SEGOVIA Y SEPÚLVEDA ENTRE LOS SIGLOS XI Y XIII: SIMILITUDES Y DIVERGENCIAS ROCÍO MAIRA VIDAL}

auxiliares de madera, reduciendo su cantidad y el coste general. Estas estructuras auxiliares eran difícilmente recuperables y reutilizables ${ }^{97}$. Ubicadas a la intemperie durante meses y sometidas al ritmo de la obra y a la acidez de los morteros de cal, se deteriorarían rápidamente, lo que aconsejaba reducir su número en lo posible.

\section{TÉCNICAS CONSTRUCTIVAS Y RECURSOS EMPLEADOS EN LA CONSTRUCCIÓN DE LAS IGLESIAS}

Segovia se sitúa en el límite entre dos estratos geológicos, al noroeste dispone de calizas y dolomías y al sureste de gneises y granitos ${ }^{98}$. Entre los materiales utilizados en sus iglesias, predomina la piedra, fundamentalmente la caliza. En algunos casos se utilizó granito, aunque se reservaba para la construcción de partes muy concretas de los muros, como los pisos bajos de la torre ${ }^{99}$ o el zócalo de refuerzo en la cara exterior de la cabecera $^{100}$. Es un material muy duro, lo que plantea una mayor dificultad en su talla respecto de la caliza y tiempos más largos de ejecución, sin embargo, aporta una mayor durabilidad, especialmente en aquellas zonas expuestas a la erosión y las humedades de capilaridad. Su utilización, siempre combinada con la caliza, se encuentra en las iglesias de San Andrés, San Justo, San Nicolás de Bari, El Salvador y la Veracruz ${ }^{101}$. Su disponibilidad no resultaba problemática por la cercanía de la Sierra de Guadarrama hacia el sur, aunque probablemente su transporte y extracción eran más costosos que la caliza, porque las canteras se situaban en la vertiente norte de la sierra, cerca de San Lorenzo ${ }^{102}$, con pendientes que dificultarían el transporte de cargas pesadas. En todo caso la mayor desventaja de este material es la dificultad de su labra, lo que no aconsejaba su uso de forma generalizada.

El ladrillo también se utilizó de manera puntual, normalmente en las torres ${ }^{103}$, ampliaciones y elementos aislados ${ }^{104}$. Su presencia en los muros suele estar asociada al sistema constructivo utilizado, formando verdugadas entre los distintos cajones de calicanto o entre los distintos tramos en altura de los muros de mampostería. Solo se utilizó de forma generalizada en la iglesia de San Martín, aunque su uso está asociado a una segunda fase de la construcción ${ }^{105}$. La ciudad no debía contar con una importante infraestructura de

97 Debía tratarse de tablones arriostrados con rollizos ligeramente desbastados, cuyos solapes y empalmes se ejecutarían con cuerdas.

98 Díez Herrero, Andrés. «El empleo de las rocas y los minerales en la arquitectura románica de la provincia de Segovia». En Enciclopedia del románico en Castilla y León. Segovia. Tomo I. Aguilar de Campoo: Fundación Santa María la Real, 2007, pp. 203-225.

99 En San Justo, el Salvador y la Veracruz.

100 En San Andrés, San Juan de los Caballeros, San Nicolás de Bari y San Lorenzo.

101 Se utilizó también en los pórticos de las iglesias de San Martín, San Esteban y San Lorenzo.

102 Díez Herrero, «El empleo», pp. 203-225.

103 En San Andrés y El Salvador.

104 En San Justo, se utilizó en el arco triunfal, con ladrillos colocados a rosca y orientados en torno a tres centros, solución típicamente musulmana.

105 Lo encontramos también en San Lorenzo y San Pedro de los Picos. 
hornos de ladrillo ${ }^{106}$ aunque si debieron construirse varios de ellos para producir la gran cantidad de cal que habría sido necesaria ${ }^{107}$ en la construcción de estas iglesias, máxime teniendo en cuenta que algunas de ellas debieron solaparse en el tiempo ${ }^{108}$.

Únicamente encontramos dos iglesias donde se ha utilizado una sola técnica constructiva: San Juan de los Caballeros y la Santísima Trinidad, construidas en sillería. Es el sistema de mayor coste porque requería mano de obra especializada en cantería, y además el transporte se encarecía por la dificultad de traslado desde la cantera. Es posible que buena parte del material llegara ya desbastado ${ }^{109}$, dejando pendientes únicamente los remates finales de las piezas para realizarlos a pie de obra, reduciendo el peso del transporte para abaratar su coste.

En otros edificios las distintas fases de construcción se pueden diferenciar por el material empleado. En la iglesia de San Lorenzo, como ocurre en la Santísima Trinidad ${ }^{110}$, se utilizó la sillería para construir la cabecera tardorrománica, sin embargo se emplearon técnicas menos costosas, como el encofrado de calicanto, en la nave y la torre, construidas en una fase anterior. En Santo Tomás, también se utilizó sillería, excepto en su pórtico gótico, obra posterior de mampostería y ladrillo. La torre de San Millán pertenecía a la construcción anterior y es la única parte del edificio ejecutada con encofrado de calicanto. El edificio actual, que sustituyó a la primera iglesia, se construyó enteramente de sillería. El caso contrario en cuanto a la sucesión de las técnicas empleadas lo encontramos en San Martín. En una primera fase se realizaron las zonas bajas de las naves con sillería. Posteriormente se amplió el edificio hacia la cabecera, construyendo el transepto y sus tres ábsides escalonados ${ }^{111}$. En esta segunda fase, se utilizó sillería en la cabecera y ladrillo en el resto de espacios, incluidos los refuerzos y partes altas de la nave ya ejecutada. Esta iglesia constituye un ejemplo muy particular de la arquitectura segoviana, donde el

106 En la arquitectura civil de Segovia la presencia del ladrillo es mayor que en la arquitectura eclesiástica, aunque sigue siendo menos numerosa que la piedra. Esta demanda estable por parte de la población habría estimulado la construcción de hornos permanentes de ladrillo y teja, abaratando su coste; sin embargo, su uso en la construcción de una iglesia, como en el caso de San Martín, habría requerido de una mayor infraestructura.

107 La cal se utilizaba como aglomerante y revoco. Proviene de la calcinación de rocas carbonaticas. En un primer momento se podrían haber fabricado hornos de cal en cualquier lugar improvisado sin embargo posteriormente debieron concentrarse en áreas con disponibilidad de granito, para la fabricación de los hornos, y de calizas de escaso contenido en arena. Se conservan hornos históricos en Sepúlveda, pero no en Segovia. Díez Herrero, Andrés. «El empleo», pp. 203-225.

108 El barrio de canonjías nos permite imaginar la alta demanda de cal que debió de producirse en los siglos XII y XIII, necesaria para la construcción de las iglesias y las viviendas de la ciudad.

109 Bechmann, Roland. "Comment standardisation et préfabrication, développées aux XII ${ }^{\mathrm{e}}$-XIII ${ }^{\mathrm{e}}$ siècles dans le système de construction, ont permis l'extraordinaire floraison des cathédrales "gothiques»». En Nègre, Valerie, Carvais, Robert, Guillerme, André, Sakarovitch, Joël (eds.). Edifice \& Artifice. Histoires Constructives. Actes du Premier Congrès Francophone d'Histoire de la Construction. París 19-21 de Junio 2008. París: Picard, 2010, pp. 771-780.

${ }_{110}$ El edificio anterior, de nave única y ábside semicircular construidos en mampostería, quedó destruido tras un incendio. La iglesia actual conserva el antiguo ábside como capilla sur. Su sistema constructivo delata un aumento de los recursos empleados frente al anterior al haberse ejecutado completamente de sillería.

111 Merino de Cáceres, José Miguel. "La iglesia de San Martín de Segovia. Análisis morfológico y evolutivo». Estudios segovianos, 2005, vol. 48, n. ${ }^{\circ} 105$, pp. 219-262. 
ladrillo se emplea con profusión, constituyendo un elemento residual en el resto de la arquitectura eclesiástica medieval de la ciudad.

En la mayor parte de las iglesias se utilizaron varias técnicas constructivas (fig. 5), en algunos casos con la clara intención de abaratar los costes. En San Andrés, el ábside central y las esquinas del edificio se ejecutaron con sillería, por el contrario, el ábside sur y el cuerpo bajo de la torre se realizaron con mampostería. El desarrollo de la torre en altura es el único elemento de ladrillo. En otros edificios, se optó por la economía de medios utilizando las técnicas menos costosas. Es el caso de San Blas y San Marcos, donde los únicos sillares los encontramos en las esquinas para reforzar los muros contra la erosión, sin embargo, su ejecución se realizó con mampostería en el primer caso y encofrado de calicanto en el segundo. En la iglesia de San Pedro de los Picos, la sillería sólo se utilizó en la portada, empleando los encofrados de calicanto en los muros y la torre, utilizando el ladrillo en las verdugadas y las esquinas. En la iglesia de San Quirce, aunque solo se conservan la cabecera, la torre y el husillo, se percibe que la sillería se reservó para los elementos de protección; las partes bajas de los muros y las esquinas. En el resto de la fábrica se utilizó mampostería, y en la torre encofrado de calicanto. En la iglesia de la Veracruz, se utilizó mampostería encofrada, entre verdugadas de ladrillo en el ábside norte. La sillería se encuentra en esquinas, contrafuertes y portadas, así como en el cuerpo inferior y superior de la torre, pero no en el intermedio.

En algunas iglesias, se reservaban los materiales y actividades de mayor coste para construir ciertas zonas del edificio, lo que delata la importancia de estos espacios frente a otros. Es el caso de la iglesia de San Clemente, donde se emplea la sillería para el ábside principal, el pórtico y el husillo, utilizando la mampostería en los muros, el ábside sur y la torre. En San Nicolás de Bari, también se emplea la sillería en el ábside central y el husillo, y en este caso también en el cuerpo alto de la torre, siendo de encofrado de calicanto el resto de la fábrica original ${ }^{112}$. En otras iglesias, como San Justo, estos elementos son el cuerpo alto de la torre y la portada, o en la iglesia de San Sebastián el ábside, el pórtico y el cuerpo bajo de la torre. El resto de la fábrica es de mampostería en la primera y de encofrado de calicanto en la segunda. En la iglesia de Santa Eulalia, aunque únicamente se conservan originales el pórtico sur, el presbiterio meridional, la torre y parte de los muros de la iglesia, se trata de un caso similar. La sillería se reservó para la torre y la portada sur, siendo los muros de mampostería encofrada.

Es en las torres donde encontramos una mayor variedad de los aparejos utilizados, combinando diferentes materiales y técnicas en altura (fig. 2). En la torre de la iglesia de El Salvador, se emplean tres técnicas distintas con diferentes materiales: el cuerpo bajo de sillarejo de granito, el cuerpo intermedio de encofrado de calicanto y el cuerpo superior de sillería de caliza. En la torre de San Andrés, el cuerpo bajo es de mampostería de caliza mientras que la parte superior es de ladrillo. En San Justo, los dos primeros cuerpos son de mampostería de granito colocada a espejo, el primero de ellos con verdugadas de ladrillo, sin embargo, la parte superior es de sillería de caliza. En San Lorenzo y en San Nicolás, el cuerpo bajo es de encofrado de calicanto mientras que el superior es de ladrillo en la primera y de sillería en la segunda. En la torre de San Sebastián, se

112 El ábside norte y los cuerpos bajos de la torre. 
IDENTIDAD Y DIMENSIÓN SOCIAL DE LA CONSTRUCCIÓN PLENOMEDIEVAL ECLESIÁSTICA

invierte la posición de las distintas técnicas, reservando la sillería para el cuerpo bajo y la mampostería encofrada para el superior. En la Veracruz, los cuatro cuerpos superpuestos se construyeron con distintas técnicas, el basamento es de sillería de granito, el cuerpo siguiente de mampostería encofrada, el tercero de mampostería y el cuarto nuevamente de sillería, pero en esta ocasión de caliza.

Las torres son un elemento singular en Segovia. Hasta la más pequeña de las iglesias contaba con una y su tamaño no es desdeñable. Las distintas técnicas constructivas utilizadas podrían indicar diferentes fases en su construcción, aunque es más probable que estén relacionadas con un intento de abaratar su coste, ya que no era una estructura económica por la cantidad de andamiaje y la altura de las grúas necesarias para elevar los materiales hasta la cota deseada. Quizá por ello en la mayor parte de las torres se reserva el material de mayor coste para el cuerpo bajo o el superior. En el primer caso, se trataría de evitar una mayor erosión e incluso entorpecer su asalto desde el acceso. En el segundo, ofrecería protección frente al alcance de posibles ataques externos. Además, siendo la parte más visible desde el exterior de la población y desde los barrios aledańos, el uso de materiales nobles proporcionaría una imagen de robustez y poder, representativa de la población de ese sector de la ciudad.

Sepúlveda se encuentra enclavada en una tierra rica en calizas y dolomías, material utilizado en la totalidad de las iglesias de la ciudad, con excepción de Santiago y San Justo y Pastor. La primera de ellas es un ejemplo atípico por ser la única iglesia donde se utiliza ladrillo como uno de los materiales principales ${ }^{113}$. Los muros del ábside semicircular y el abovedamiento del presbiterio se ejecutaron con este material ${ }^{114}$. El ladrillo únicamente está presente en otra de las iglesias de la ciudad, San Justo y Pastor, pero aquí su uso se limitó exclusivamente a los nervios sobre los que descansa la bóveda esquifada de la torre y a las arquerías de los lienzos en su cuerpo superior ${ }^{115}$.

La técnica utilizada en la construcción de las iglesias más importantes de Sepúlveda, El Salvador, Nuestra Señora de la Peña y San Justo y Pastor, es la sillería. La torre de ésta última presenta un sistema constructivo diferente: sus muros y la bóveda que cierra el nivel superior se ejecutaron con mampostería encofrada de calicanto. Sin embargo este elemento podría ser previo a la construcción de la iglesia ${ }^{116}$, al menos su cuerpo inferior ${ }^{117}$. La iglesia de San Bartolomé ha sufrido numerosas modificaciones que únicamente nos permiten afirmar que el presbiterio y el pórtico se ejecutaron con sillería. El edificio

113 Es un caso extraño ya que los afloramientos arcillosos, de donde se extraen los materiales para la fabricación de ladrillo, se encuentran lejos, en las campiñas y llanos del centro y noroeste de la provincia de Segovia, donde se concentra la arquitectura de ladrillo.

114 El ábside cuenta con un zócalo de sillarejo. La nave, la torre y el edificio adosado en el lateral norte son de mampostería, así como todas las bóvedas del edificio con excepción de la bóveda del presbiterio.

115 En la iglesia de San Andrés, de la que solo se conservan algunos restos de su torre formando parte de una vivienda, también se utilizó ladrillo como material de refuerzo en esquinas y en las verdugadas que separan los distintos tramos de mampostería.

116 No se ha detectado ninguna discontinuidad en su fábrica que indique la posterioridad del cuerpo superior. Se consideran coetáneos y anteriores a la iglesia, quizá destinados a la defensa de la ciudad como parte del recinto amurallado.

117 Guarda ciertas similitudes con la torre de San Millán de Segovia: el material, así como la técnica constructiva de sus muros, que también se van solapando de forma alterna, y de la bóveda. 
original se podría haber realizado completamente en sillería o quizá podría haberse reservado esta técnica para la construcción de las zonas más relevantes. En la iglesia de Santiago las técnicas con mayor especialización, la sillería y el ladrillo, se reservaron para la cabecera, por ser la parte más representativa del edificio. En la nave se utilizó mampostería $^{118}$. El resto de iglesias sepulvedanas, San Pedro, San Millán y San Andrés, se realizaron con mampostería, reservando la sillería para el refuerzo de esquinas y portadas ${ }^{119}$.

Sepúlveda es el escenario opuesto al caso segoviano porque la construcción de sus iglesias es homogénea ${ }^{120}$ (fig.5). Se utilizó mayoritariamente caliza empleando dos tipos de técnicas constructivas dependiendo de la relevancia del edificio y del poder económico de la población dependiente de la parroquia: la sillería en los edificios más importantes y la mampostería en el resto.
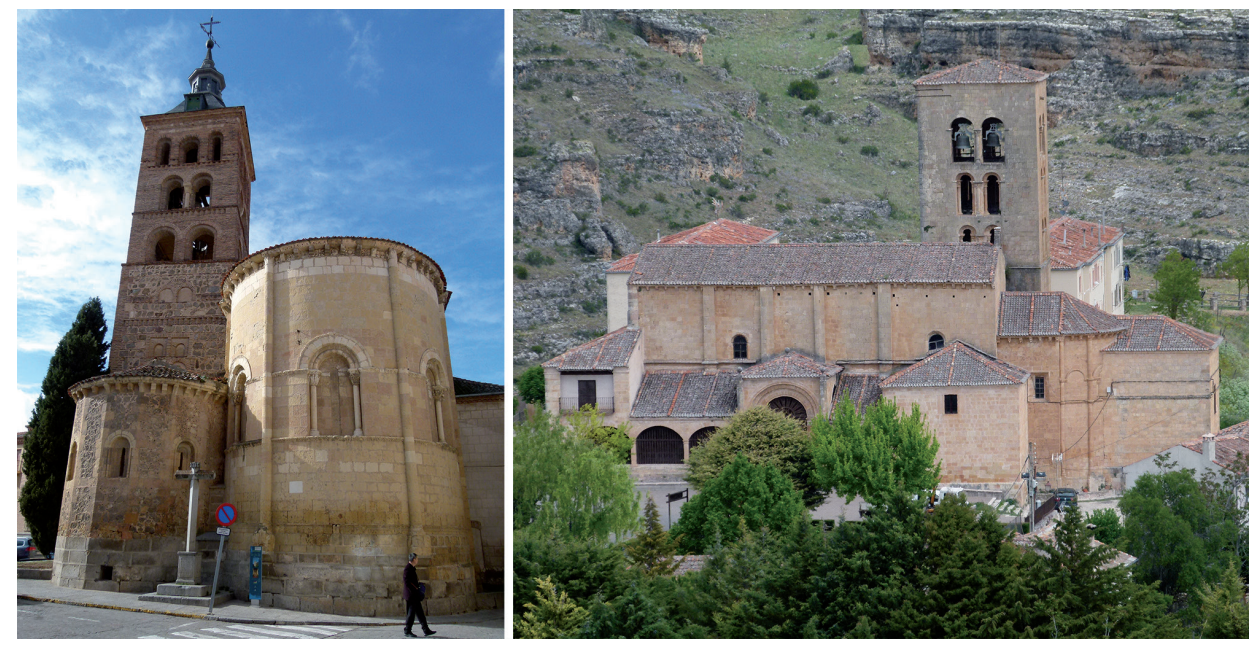

Figura 5. Izquierda iglesia de San Andrés (Segovia).

Derecha iglesia de Nuestra Señora de la Peña (Sepúlveda). Fotografías de la autora.

Tanto en Segovia ${ }^{121}$ como en Sepúlveda ${ }^{122}$ se utilizaron los materiales locales disponibles con la finalidad de minimizar el coste del transporte, probablemente una de las actividades que más encarecía la obra (fig. 5). No todas las zonas de afloramientos eran aptas para la extracción de la piedra empleada en construcción. Además las precarias

118 Se han realizado algunas reposiciones con sillería reutilizada en la esquina suroccidental de la nave.

119 En San Andrés, estos refuerzos se realizaron con ladrillo.

120 El estudio comparativo de la contraposición arquitectónica que se ha detectado en relación con la estructura social de ambos centros de poder podría aportar interesantes conclusiones, tal y como ha seńalado uno de los revisores anónimos de este texto.

121 En Segovia la caliza se extraía en las canteras de Bernuy de Porreros, Zamarramala, Tejadilla, Madrona y El Parral. El granito provenía de Las Nieves (San Lorenzo), y de Ciguińuela (La Lastrilla-Segovia). 225 .

${ }_{122}$ Las canteras de Sepúlveda son Aldehuelas, el Villar y Batán. Díez Herrero, «El empleo», pp. 203- 
IDENTIDAD Y DIMENSIÓN SOCIAL DE LA CONSTRUCCIÓN PLENOMEDIEVAL ECLESIÁSTICA

herramientas medievales no facilitaban el proceso, por ello las canteras se situaban fundamentalmente en laderas y gargantas, donde era más sencillo acceder a los estratos de roca $^{123}$.

La utilización de diferentes tipos de piedra en estas iglesias depende de la disponibilidad del material en el entorno inmediato ${ }^{124}$, de su adecuación como material de construcción y de la economía del promotor para hacer frente al coste del traslado desde largas distancias. Díez Herrero considera $1 \mathrm{~km}$. una larga distancia para este cometido. Es cierto que el traslado de material pesado complica mucho el desplazamiento por corto que sea, sin embargo, tenemos constancia de canteras situadas a 20 o 30 kilómetros de la obra. En las construcciones de grandes catedrales, estas distancias se incrementaban aún más ${ }^{125}$, sin embargo se trataba de obras con más recursos materiales y económicos ${ }^{126}$. Tratándose de iglesias de tamaño más modesto quizá habría que suponer un máximo de 20 o $30 \mathrm{~km}$. a la redonda, incluso menos en algunos casos.

\section{Hacia unas CONClusiones: los COSTES EN LA CONSTRUCCión MEDiEVAL DE Segovia y Sepúlveda}

La arquitectura medieval eclesiástica de Segovia se caracteriza por la heterogeneidad de las técnicas constructivas y los materiales empleados. Esta variedad responde a diferentes fases en la ejecución de la iglesia o a la incorporación de elementos arquitectónicos previos a las nuevas estructuras, sin embargo, también es fruto de la disponibilidad de distintos tipos de material en el entorno inmediato, a escasos kilómetros de la ciudad, y de la intención de economizar el coste del edificio. Segovia se sitúa en el encuentro de varias capas geológicas y junto a bosques con grandes especies de árboles, lo que permitió poder seleccionar el material conveniente en cada caso dependiendo de la idoneidad de sus características para el fin requerido y de los recursos económicos disponibles. Las técnicas constructivas también se seleccionaban en función de la relevancia del espacio, reservando la sillería para los elementos simbólicos, como los cuerpos altos de las torres,

123 Algunas presentan múltiples discontinuidades o la alteración de la propia roca, lo que habría imposibilitado su explotación. Los documentos góticos permiten ahora localizar las canteras medievales de Segovia, considerando que probablemente se trate de los mismos lugares de extracción por haber sido históricamente explotados. Díez Herrero, «El empleo», pp. 203-225.

124 La capacidad portante de los materiales era conocida por los maestros que seleccionaban los tipos de piedra en función de su resistencia dependiendo de su cometido. También condicionaba el tipo de aparejo que dependía del tamaño máximo de los bloques que se podían extraer en la cantera.

125 Foyle, Jonathan. Architecture of Canterbury Cathedral. London: Scala Publishers, 2013.

126 El traslado de material en el Medioevo era más sencillo por vía fluvial o marítima que por terrestre. En 1287 el transporte marítimo de la piedra de Caen para la construcción de la catedral de Canterbury solo triplicaba el precio de la carga, a pesar de tratarse de $400 \mathrm{~km}$. de distancia, sin embargo, el coste del transporte por tierra a lo largo de $18 \mathrm{~km}$. duplicaba el precio de la carga transportada. Gimpel, Jean. La revolución industrial en la Edad Media. Madrid: Taurus, 1981. En la iglesia del Monasterio de Vaucelles (Francia) la piedra utilizada en la construcción de los pilares principales provenía de canteras de la región de Tournai, situadas a $80 \mathrm{~km}$. Por el contrario, para los muros, que no soportaban el peso de las bóvedas, se utilizó la piedra local menos resistente. Bechmann, «Comment», pp. 771-780. 
IDENTIDAD Y DIMENSIÓN SOCIAL DE LA CONSTRUCCIÓN PLENOMEDIEVAL ECLESIÁSTICA EN SEGOVIA Y SEPÚLVEDA ENTRE LOS SIGLOS XI Y XIII: SIMILITUDES Y DIVERGENCIAS ROCÍO MAIRA VIDAL

o con una función destacada en el edificio y en la ciudad, como la cabecera, los pórticos y los nártex.

Las iglesias segovianas eran edificios cambiantes, que se iban adaptando sucesivamente a nuevos escenarios y a las demandas de sus habitantes. Primero se construyeron las iglesias y posteriormente se fueron ańadiendo nuevos elementos, como las torres y los pórticos, ocupando diferentes espacios para adaptarse a la morfología de la ciudad. Las torres podrían haberse ańadido como símbolos de su poder una vez que aseguró su posición dominante sobre Cuéllar y Sepúlveda. Al igual que las iglesias, con distintas técnicas constructivas en cada nivel, presentan una imagen heterogénea. Por otro lado, existe una clara intención de abaratar costes reservando los sistemas más sencillos y económicos para las zonas menos visibles y accesibles, como el interior de la parte alta de las torres. Los pórticos podrían haberse añadido como respuesta a los cambios sociales que se produjeron en la ciudad al constituirse como nuevo centro de poder de las ciudades de Villa y Tierra, lo que podría haber atraído nuevos pobladores que requerían un mayor número de espacios de relación social. La orientación sur, la más habitual, era la más adecuada teniendo en cuenta la climatología para albergar actividades colectivas. La existencia de varios pórticos, quizá construidos de forma sucesiva, estaría relacionada con las actividades públicas que albergaban y con la población a la que daban servicio, estableciendo un lazo entre las funciones religiosas y las laicas. La adición de estos nuevos elementos, cuya ejecución era costosa, enriquecía el edificio mostrando la relevancia y dinamismo de la ciudad. El espacio interior de las iglesias más representativas era más complejo que el de las iglesias sepulvedanas, destacando el crucero y las tipologías de abovedamientos utilizadas.

La ciudad de Sepúlveda muestra un panorama mucho menos variado. Refleja una imagen estática que corresponde al momento de mayor auge de la ciudad, en el que se llevan a cabo la mayor parte de los edificios eclesiásticos. Su arquitectura se construye en distintas fases consecutivas, en un periodo de tiempo relativamente corto, por lo que al contrario que en Segovia su imagen es homogénea. Las iglesias no contaban con edificios precedentes de cierta envergadura, como sí ocurrió en Segovia. Sus torres, exentas y con doble abovedamiento interior, parecen haberse construido como elementos defensivos. $\mathrm{Su}$ arquitectura eclesiástica se podría agrupar en dos tipologías en función del coste de su ejecución. Por un lado, las grandes iglesias construidas en sillería, donde el material y la técnica empleados parecen constituir un símbolo del poder económico de sus feligreses. Por el contrario, aquellas iglesias más humildes, donde los materiales y las técnicas utilizadas son más económicas y reflejan una condición distinta de la población que pertenecía a estos barrios. Estas iglesias se han conservado peor y muchas de ellas han desaparecido total o parcialmente. La utilización del material local disponible, la caliza, contribuyó a la imagen homogénea de la arquitectura de la ciudad.

En un momento de la historia en el que la comunicación terrestre entre las distintas poblaciones era todavía complicada, el traslado de material y de cargas pesadas para llevar a cabo la construcción de nuevos edificios suponía uno de los mayores impedimentos para realizar estas estructuras, especialmente en los casos de las iglesias locales, con menores recursos frente a las grandes catedrales y monasterios. La población optaba 
IDENTIDAD Y DIMENSIÓN SOCIAL DE LA CONSTRUCCIÓN PLENOMEDIEVAL ECLESIÁSTICA

por explotar los recursos locales, adaptando las distintas técnicas y la especialización de la mano de obra a las diferentes partes del edificio, adecuando el coste a su capacidad económica.

\section{Bibliografía}

Albizu y Sainz de Murieta, Juan. San Cernin. Reseña histórico-artística de la iglesia parroquial de San Saturnino de Pamplona. Pamplona: Editorial Aramburu, 1930.

Alfaro Suescun, Egoitz. «La arquitectura eclesiástica en Álava y Treviño durante los siglos XII-XIII: promotores, constructores y significados en un momento de transición». Arqueología de la Arquitectura, 2017, vol. 14, pp. 1-28.

Asenjo González, María. "La repoblación de las Extremaduras (s. X-XIII)». En Actas del coloquio de la $V$ asamblea general de la sociedad española de estudios medievales. Zaragoza: Departamento de Cultura y Educación, 1991, pp. 73-99.

Bartolomé Herrero, Bonifacio. «Espacio, Iglesia y Sociedad en las Tierras de Segovia durante los siglos XI y XII». En Enciclopedia del románico en Castilla León. Segovia. Tomo I. Aguilar de Campoo: Fundación Santa María la Real, 2007, pp. 17-47.

Bechmann, Roland. "Comment standardisation et préfabrication, développées aux XII ${ }^{\mathrm{e}}-\mathrm{XIII}^{\mathrm{e}}$ siècles dans le système de construction, ont permis l'extraordinaire floraison des cathédrales «gothiques»». En Nègre, Valerie, Carvais, Robert, Guillerme, André, Sakarovitch, Joël (eds.). Edifice \& Artifice. Histoires Constructives. Actes du Premier Congrès Francophone d'Histoire de la Construction. París 19-21 de Junio 2008. París: Picard, 2010, pp. 771-780.

Choisy, Auguste. El arte de construir en Roma. Madrid: Instituto Juan de Herrera, 1999.

Díez Herrero, Andrés. «El empleo de las rocas y los minerales en la arquitectura románica de la provincia de Segovia». En Enciclopedia del románico en Castilla y León. Segovia. Tomo I. Aguilar de Campoo: Fundación Santa María la Real, 2007, pp. 203-225.

Foyle, Jonathan. Architecture of Canterbury Cathedral. London: Scala Publishers, 2013.

Fuentes González, Paula. Bóvedas de arcos entrecruzados entre los siglos X y XVI. Geometría, construcción y estabilidad. Tesis doctoral. Universidad Politécnica de Madrid, 2013.

Gimpel, Jean. La revolución industrial en la Edad Media. Madrid: Taurus, 1981.

Giovannini, Fabio y Capdevila Montes, Enrique. «La petrificación de una villa: historia social de una villa a través de la arqueología de la arquitectura». En VI Congreso de Arqueología Medieval (España-Portugal). Alicante, 7 al 9 de Noviembre de 2019. (En prensa).

Maira Vidal, Rocío. «La estereotomía románica: trazas y cortes de cantería en la iglesia de San Juan de Rabanera». En Huerta, Santiago, Redondo Martínez, Esther, Gil Crespo, Ignacio Javier, y Fuentes, Paula (Eds.). Actas del Undécimo Congreso Nacional de Historia de la Construcción. Soria, 9-12 de octubre de 2019. Volumen II. Madrid: Instituto Juan de Herrera, 2019, pp. 645-654.

Martínez Díez, Gonzalo. «La repoblación de la Extremadura castellana y las Comunidades de Villa y Tierra». En Muñoz Gómez, Víctor (coord.). Las Comunidades de Villa y Tierra: dinámicas históricas y problemáticas actuales. Murcia: Editum, 2012, pp. 19-36.

Merino Gómez, Elena. Torres medievales en la Baja Moraña (Ávila): análisis constructivo, histórico y artístico a partir de su documentación gráfica. Tesis doctoral. Universidad de Valladolid, 2011.

Merino de Cáceres, José Miguel. «La torre de la iglesia de San Millán en Segovia». En Huerta Fernández, Santiago (ed.). Actas del Cuarto Congreso Nacional de Historia de la Construcción. Cádiz, 27-29 de enero de 2005. Madrid: Instituto Juan de Herrera, 2005, pp. 771-779. 
Merino de Cáceres, José Miguel. «La iglesia de San Martín de Segovia. Análisis morfológico y evolutivo». Estudios Segovianos, 2005, vol. 48, n. ${ }^{\circ}$ 105, pp. 219-262.

Palacios Gonzalo, José Carlos. La Cantería Medieval. La construcción de la bóveda gótica española. Madrid: Editorial Munilla-Lería, 2009.

Ruiz Hernando, José Antonio. La arquitectura de ladrillo en la provincia de Segovia siglos XII y XIII. Segovia: Excma. Diputación Provincial de Segovia, 1988.

Ruiz Hernando, José Antonio. "La arquitectura medieval en Segovia». En Segovia 1088-1988. Congreso de historia de la ciudad. Actas. Segovia: Junta de Castilla y León, 1991, pp. 127-172.

Ruiz Hernando, José Antonio. "El románico en Segovia». En Enciclopedia del románico en Castilla y León. Segovia. Tomo I. Aguilar de Campoo: Fundación Santa María la Real, 2007, pp. 4988.

Ruiz Hernando, José Antonio. «El románico civil». En Enciclopedia del románico en Castilla León. Segovia. Tomo I. Aguilar de Campoo: Fundación Santa María la Real, 2007, pp. 89-201.

Ruiz Hernando, José Antonio, Rodríguez Montañés, José Manuel, García Guinea, Miguel Ángel y Pérez González, José María. Enciclopedia del románico en Castilla y León. Segovia. Tomos I y III. Aguilar de Campoo: Fundación Santa María la Real, 2007.

Sainz Esteban, Alicia. Las murallas en las comunidades de villa y tierra de la diócesis de Segovia en los siglos XI a XIII. Técnica y sistemas constructivos de la arquitectura defensiva medieval. Tesis doctoral. Universidad de Valladolid, 2017.

Salgado Pantoja, José Arturo. Pórticos románicos en las tierras de Castilla. Aguilar de Campoo: Fundación Santa María la Real, 2014.

Villar García, Luis Miguel. «La formación de las Comunidades de Villa y Tierra en las fronteras del Duero». Biblioteca: Estudio e investigación, 2009, vol. 24, pp. 77-103. 